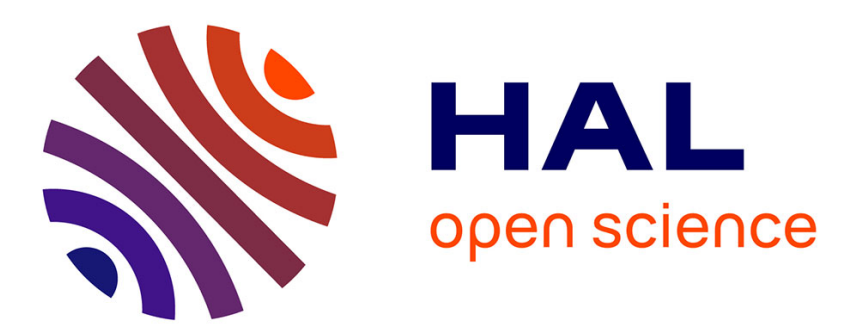

\title{
Performance of modern density functional theory for the prediction of hyperfine structure: meta-GGA and double hybrid functionals
}

\author{
Frank Neese, Barbara Kirchner, Simone Kossmann
}

\section{- To cite this version:}

Frank Neese, Barbara Kirchner, Simone Kossmann. Performance of modern density functional theory for the prediction of hyperfine structure: meta-GGA and double hybrid functionals. Molecular Physics, 2008, 105 (15-16), pp.2049-2071. 10.1080/00268970701604655 . hal-00513134

\author{
HAL Id: hal-00513134 \\ https://hal.science/hal-00513134
}

Submitted on 1 Sep 2010

HAL is a multi-disciplinary open access archive for the deposit and dissemination of scientific research documents, whether they are published or not. The documents may come from teaching and research institutions in France or abroad, or from public or private research centers.
L'archive ouverte pluridisciplinaire $\mathbf{H A L}$, est destinée au dépôt et à la diffusion de documents scientifiques de niveau recherche, publiés ou non, émanant des établissements d'enseignement et de recherche français ou étrangers, des laboratoires publics ou privés. 


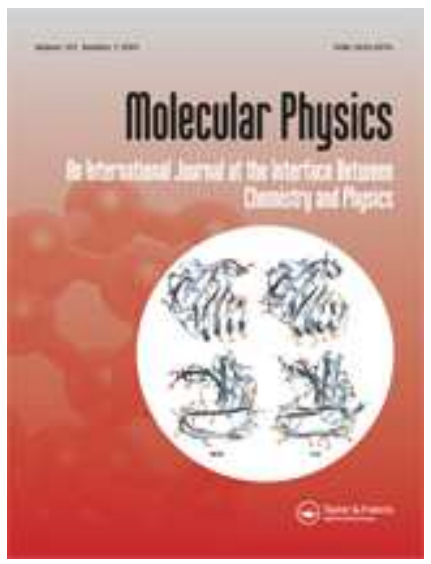

\section{Performance of modern density functional theory for the prediction of hyperfine structure: meta-GGA and double hybrid functionals}

\begin{tabular}{|r|l|}
\hline Journal: & Molecular Physics \\
\hline Manuscript ID: & TMPH-2007-0129.R1 \\
\hline Manuscript Type: & Full Paper \\
\hline Date Submitted by the & $14-J u l-2007$ \\
\hline Complete List of Authors: & $\begin{array}{l}\text { Neese, Frank; Bonn University, Institute for Physical and } \\
\text { Theoretical Chemistry } \\
\text { Kirchner, Barbara; Universität Leipzig, Chemie } \\
\text { Kossmann, Simone; Institut für Physikalische und Theoretische } \\
\text { CHemie, Universität Bonn }\end{array}$ \\
\hline Keywords: & $\begin{array}{l}\text { EPR, Hyperfine couplings, density functional theory, double hybrid, } \\
\text { meta GGA }\end{array}$ \\
\hline $\begin{array}{l}\text { Note: The following files were submitted by the author for peer review, but cannot be converted } \\
\text { to PDF. You must view these files (e.g. movies) online. }\end{array}$ \\
\hline TMPH-2007-0129.R1.tex \\
\hline
\end{tabular}

\section{scholarONE" \\ Manuscript Central}




\title{
Performance of modern density functional theory for the prediction of hyperfine structure: meta-GGA and double hybrid functionals
}

\author{
Simone Koßmann ${ }^{\dagger}$ and Barbara Kirchner ${ }^{\S}$ and Frank Neese ${ }^{\dagger \star a}$ \\ $\dagger$ Institut für Physikalische und Theoretische Chemie, \\ Universität Bonn, Wegelerstr. 12, D-53115 Bonn, Germany \\ $\S$ Wilhelm-Ostwald Institut für Physikalische und Theoretische Chemie, \\ Universität Leipzig, Linnestr. 2, D-04103 Leipzig, Germany
}

\begin{abstract}
The performance of modern density functionals for the prediction of molecular hyperfine couplings is investigated for a series of small radicals and transition metal complexes. Besides the established BP86 (GGA) and B3LYP (hybrid) functionals we have tested two prototypical members of emerging classes of density functionals, namely the TPSS meta-GGA functional (together with its hybrid version TPSSh) and the B2PLYP double-hybrid functional. The latter is the first member of a 'fifth-rung' density functional that incorporates a fraction of orbital dependent nonlocal correlation energy estimated at the level of second order many-body perturbation theory. Since this approach is non-variational, it becomes necessary to derive and implement the so-called 'relaxed' densities in order to properly predict hyperfine couplings. The necessary formalism is described in some detail and the new method has been implemented into the ORCA electronic structure program. The results of extended test calculations reveal that TPSS is superior to BP86. The hybrid variant TPSSh is at least as accurate or better than the B3LYP functional and significantly superior to the nonhybrid TPSS variant. The B2PLYP functional also leads to accurate predictions and is a clear improvement for the difficult metal nucleus HFCs. However, it also showed a few significant outliers in the test set which points to a somewhat reduced stability in the method. The latter effect is largely attributed to the elevated fraction Hartree-Fock exchange (53\%) and to some extent also to the perturbative correction.
\end{abstract}

Date: July 30, 2007

Status: submitted to Molecular Physics

aemail: neese@thch.uni-bonn.de 


\section{Introduction}

Electron paramagnetic resonance (EPR) is presently a florishing field of investigation. Owing to the enormous progress that has been made in the experimental techniques, it is now possible to determine spin-Hamiltonian $(\mathrm{SH})$ parameters of molecules with unprecedented precision. [1] Concomitant with the progress in the experimental technology it is necessary to develop new theoretical techniques that allow for a precise prediction of SH parameters. To an increasing extent, this becomes a necessary complement to the experimental investigations in order to allow for a detailed interpretation of the experimental data. In particular, theoretical calculations may yield excellent starting values for simulations, provide good estimates of tensor orientations ( $\mathrm{cf}[2]$ ) and reveal the molecular geometric and electronic structure origin of the observed spectral features. A recent book broadly covers [3] this field and an up to date presentation of the underlying theory may be found in refs $[4,5]$.

Perhaps the most accessible SH parameter and the one that carries the largest amount of geometric information is the hyperfine coupling (HFC). Since the early days of EPR spectroscopy, it has been a point of focal interest to interpret the HFCs of organic radicals [6-12] and transition metal complexes. $[13,14]$ For quantum chemistry, the HFC is a difficult property. It is well known that the HFC contains three contributions: (a) the isotropic Fermi contact term, (b) the spin-dipolar contribution and (c) a spin-orbit coupling (SOC) correction. For radicals made of light elements and also for light nuclei, the SOC contribution is very small and may be disregarded. [15] For rapidly tumbling radicals in fluid solution, the spin-dipolar part averages to zero. [16] This means that under these conditions the EPR spectra are dominated by the isotropic Fermi contact term. This is a highly singular property that depends on the spin-density of the nucleus in question [17] (for alternative approaches and discussions see [18-21]). Thus, the precise prediction of hyperfine couplings requires a high accuracy wavefunction in the vicinity of the nucleus in question. From a technical point of view, this requires very flexible basis sets in the core region and an accurate description of core level spin-polarization. Since the Hartree-Fock method disastrously overshoots this core level spin-polarization [22,23], elaborate ab initio treatments are required to reach high precision in the Fermi contact term. Experience suggests that at the level 
of the quadratic configuration interaction or coupled cluster theory with single and double excitations (QCISD and CCSD) excellent predictions are obtained. [24-29] However, the computational complexity of these methods scales as the sixth power of the molecular size and presently, they can not be applied to many molecules of chemical interest. Thus, it may be considered as fortunate that density functional theory (DFT) has been shown to yield fairly reasonable values for isotropic hyperfine couplings. Since the first reports [30-32] there has been much activity in testing new density functionals in their application to radical EPR spectra. [33-39] There appears to be consensus that overall, hybrid density functionals yield the best predictions. Since the B3LYP functional [40-42] is already the "workhorse" of quantum chemistry, it is perhaps the most well established choice and its predictions for HFCs are often very good. [26] The dipolar hyperfine tensors of radicals appear to be less problematic and are usually well predicted by many theoretical approaches including DFT. Hyperfine calculations on organic radicals have recently been reviewed by Improta and Barone [26] and impressive combinations of EPR calculations with molecular dynamics have been developed and highlighted by Polimeno and Barone. [43] Asher and Kaupp have recently investigated the influence of the solvation shell on the HFCs of the benzosemiquinone radical anion employing Car-Parrinello molecular dynamics in combination with EPR calculations. [44]

The success of DFT based methods for HFC predictions decreases somewhat upon going to transition metal complexes. In this area, all theoretical methods have difficulties to arrive at precise values. Ab initio methods have a very restricted range of applicability in this field. [35,45] DFT methods, although reasonable, have problems to generate accurate values. First of all, the SOC contributions to the HFC are often large $[3,46,47]$, the spin-polarization of the metal-core is usually underestimated $[36,47]$ and the exagarated metal-ligand covalency leads to an underestimation of the spin-dipolar parts. [47,48] The SOC contribution to the HFC is a response property [47] that is closely related to the theory of the g-tensor, as is well known from ligand-field theory. [13,14] Since g-shifts tend to be underestimated by present day density functionals the same has to be expected for the SOC contribution to the metal nucleus HFC. The results obtained so far are consistent with these expectations. $[46,47,49]$ From the preceding discussion it becomes evident that it is an important issue to test the 
newly emerging functionals in their capability to predict accurate HFCs for radicals and transition metal complexes. Applications of DFT to chemistry started with the local density approximation (LDA) that provided reasonable results but was quickly realized to be too inaccurate for general chemistry purposes. This changed dramatically upon the introduction of the generalized gradient (GGA) functionals that also contain the first derivatives of the electron density in their definition. GGA functionals such as the BLYP, [40,42], BP86 [40, 50] and PBE [51] functionals have opened the door for extremely successful modeling of a wide range of chemical problems at low computational cost. A substantial, though largely semi-empirical, improvement to GGA functionals was made by Becke who introduced the concept of hybrid functionals that contain a fraction of the exact, nonlocal and orbital dependent exchange term in their definition. [41,52] Indeed, since the introduction of the B3LYP functional [40-42], which contains three empirical parameters, it has emerged as the most widely used method for general chemistry that, on average, yields the most accurate predictions for a wide range of molecular properties and energetics. However, even the B3LYP functional has its limitations and consequently, new functionals are being developed at rapid pace. A development beyond the reparameterization of existing GGA or hybridGGA functionals are the introduction of meta-GGAs [53] which contain the kinetic energy density and perhaps the second derivatives of the electron density in their definition. The most widely recognized functional of this type is the TPSS functional that has already seen significant chemical applications. [54] Secondly, Grimme has recently suggested a novel class of 'double-hybrid' (DHDF) functionals which contain a fraction of nonlocal, orbital dependent correlation estimated at the level of second-order many body perturbation theory (MBPT). [55] The new DHDFs have given impressive results in benchmark calculations: energetic quantities are predicted with an average error of less than $2 \mathrm{kcal} / \mathrm{mol}$ which is the lowest ever achieved error for any density functional. Following the development of analytic gradients for this method [56] it was determined that the results obtained for molecular structures are also very accurate. The prototypical member of the DHDFs is the B2PLYP functional which contains two empirical parameters that control the amount of HF exchange and MBPT correlation. Their values are close to 50 percent HF exchange and 25 percent MBPT correlation. 


\section{Theory}

In the language of analytic derivative theory, the HFC is defined as the second mixed derivative of the total ground state energy with respect to the electron spin $\hat{S}$ as well as to the nuclear spin $\hat{I}$, eq. (1)

$$
A_{\mu \nu}=\frac{\partial^{2} E}{\partial \hat{S}_{\mu} \partial \hat{I}_{\nu}^{(A)}} .
$$

The hyperfine coupling tensor for the nucleus 'A' consists of three contributions, which are the isotropic Fermi contact (FC) and the anisotropic spin-dipolar contributions (SD) (both to first order in perturbation theory) and SOC contribution (to second order in perturbation theory):

$$
A_{\mu \nu}^{A}=A_{\mu \nu}^{(A ; c)}+A_{\mu \nu}^{(A ; d)}+A_{\mu \nu}^{(A ; S O)} .
$$


The expressions for the three parts of the HFC are explicitly given by,

$$
\begin{aligned}
A_{k l}^{(A ; c)} & =\delta_{k l} \frac{8 \pi}{3} \frac{1}{2 S} g_{e} g_{N} \beta_{e} \beta_{N} \rho^{\alpha-\beta}\left(\vec{R}_{A}\right) \\
A_{k l}^{(A ; d)} & =\frac{1}{2 S} \sum_{\mu \nu} P_{\mu \nu}^{\alpha-\beta}\left\langle\varphi_{k}\left|\vec{r}_{A}^{-5}\left({\overrightarrow{r_{A}}}^{2} \delta_{\mu \nu}-3 \vec{r}_{A ; \mu} \vec{r}_{A ; \nu}\right)\right| \varphi_{\tau}\right\rangle \\
A_{k l}^{(A ; S O)} & =-\frac{1}{S} g_{e} g_{N} \beta_{e} \beta_{N} \sum_{\mu \nu} \frac{\partial P_{\mu \nu}^{\alpha-\beta}}{\partial \hat{I}_{k}^{(A)}}\left\langle\varphi_{\mu}\left|\hat{z}_{l}^{S O M F}\right| \varphi_{\nu}\right\rangle .
\end{aligned}
$$

$g_{e}$ is the free-electron g-value, $g_{N}$ the nuclear g-value of the nucleus in question. $\beta_{e}$ and $\beta_{N}$ are the Bohr and the nuclear magneton, respectively. $\rho^{\alpha-\beta}\left(\vec{R}_{A}\right)$ and $P_{\mu \nu}^{\alpha-\beta}$ indicate the spin density on the position of nucleus $A$ and the spin density matrix $P_{\mu \nu}^{\alpha-\beta}=P_{\mu \nu}^{\alpha}-P_{\mu \nu}^{\beta}$. The indices $\mu, \nu, \kappa, \tau$ refer to basis functions. The SOC operator is taken in the meanfield approximation (SOMF). [57] The SOMF operator is an effective one-electron spin-orbit operator, which includes both the direct and the exchange interactions between the outer valence and the core electrons, but handles the screening of the one-electron terms by the twoelectron contributions by means of an average over the electrons. [57] The matrix elements of the l'th component of the SOMF operator, are given by

$$
\begin{aligned}
\left\langle\varphi_{\mu}\left|\hat{z}_{l}^{S O M F}\right| \varphi_{\nu}\right\rangle= & \left\langle\varphi_{\mu}\left|\hat{z}_{l}^{1 e l-S O}\right| \varphi_{\nu}\right\rangle+\sum_{\kappa \tau}\left[\left(\varphi_{\mu} \varphi_{\nu}\left|\hat{g}_{l}^{S O}\right| \varphi_{\kappa} \varphi_{\tau}\right)-\frac{3}{2}\left(\varphi_{\mu} \varphi_{\kappa}\left|\hat{g}_{l}^{S O}\right| \varphi_{\tau} \varphi_{\nu}\right)\right. \\
& \left.-\frac{3}{2}\left(\varphi_{\tau} \varphi_{\nu}\left|\hat{g}_{l}^{S O}\right| \varphi_{\mu} \varphi_{\kappa}\right)\right]
\end{aligned}
$$

with

$$
\begin{aligned}
\hat{z}_{l}^{1 e l-S O}\left(\vec{r}_{i}\right) & =\frac{\alpha^{2}}{2} \sum_{i} \sum_{A} Z_{A} \vec{r}_{i A}^{-3} \hat{l}_{i A ; l} \\
\hat{g}_{l}^{S O}\left(\vec{r}_{i}, \vec{r}_{j}\right) & =-\frac{\alpha^{2}}{2} \hat{l}_{i j ; l} \vec{r}_{i j}^{-3} .
\end{aligned}
$$

$P_{\kappa \tau}$ is the density matrix $P_{\kappa \tau}=P_{\kappa \tau}^{\alpha}+P_{\kappa \tau}^{\beta}, Z_{A}$ the nuclear charge of atom $A, \vec{r}_{i A}$ the position of electron $i$ relative to nucleus $A$ and $\hat{l}_{i A ; l}$ is the l'th component of the angular momentum of the $i$ 'th electron relative to atom $A$. Analogously, $\vec{r}_{i j}$ is the distance between electron 
$i$ and $j$ and $\hat{l}_{i A ; l}$ is the l'th component of the angular momentum of electron $i$ relative to electron $j$.

In the case of the DHDFs the theory of the hyperfine coupling is more complicated due to the presence of the scaled second order MBPT contribution to the energy. In these methods the exchange-correlation energy is given by eqn (9).

$$
E_{x c}=\left(1-a_{x}\right) E_{x}^{B 88}+a_{x} E_{x}^{H F}+b E_{c}^{L Y P}+c E_{c}^{M P 2}
$$

The form of the second-order MBPT (MP2) energy is conventional but is calculated from the Kohn-Sham orbitals and eigenvalues. The semi-empirical coefficients are given as $a_{x}=0.53$, $b=0.73$ and $c=0.27$. The derivation and implementation of the analytic gradients of double hybrid functionals was previously reported in ref. [56]. This derivation and the associated implementation in the ORCA program enables us to treat hyperfine couplings on the basis of the new double-hybrid functionals for the first time here.

The ESR parameters presented in this paper are consistently calculated with relaxed densities, following the logics of analytic derivative theory for correlated wave functions. [58-60] The relaxed difference densities for double hybrid functionals differ from those employed for the parent MP2 method. First, the unrelaxed PT2 difference densities are defined in the MO basis, eq. $(11,12)$, whereas the SCF density is given in the AO basis, eq. (10).

$$
\begin{aligned}
\rho_{\mathbf{D}^{\prime}}^{\sigma}(\vec{r}) & =\sum_{\mu \nu} D_{\mu \nu}^{\prime \sigma} \varphi_{\mu}(\vec{r}) \varphi_{\nu}(\vec{r}) \\
\text { with } \quad D_{i j}^{\prime \sigma} & =-\sum_{k_{\sigma}}\left\langle\mathbf{t}^{i_{\sigma} k_{\sigma}} \mathbf{t}^{k_{\sigma} j_{\sigma}}\right\rangle-\sum_{k_{\sigma^{\prime}}}\left\langle\mathbf{t}^{i_{\sigma} k_{\sigma^{\prime}}} \mathbf{t}^{k_{\sigma^{\prime} j_{\sigma}}}\right\rangle \\
\text { and } \quad D_{a b}^{\prime \sigma} & =\sum_{i_{\sigma}<j_{\sigma}} \mathbf{t}^{i_{\sigma} j_{\sigma}} \mathbf{t}^{i_{\sigma} j_{\sigma}+}+\sum_{i_{\sigma^{\prime}} j_{\sigma}} \mathbf{t}^{i_{\sigma^{\prime}} j_{\sigma}+} \mathbf{t}^{i_{\sigma^{\prime}} j_{\sigma}}
\end{aligned}
$$

The indices $i, j, k, \ldots$ refer to occupied Kohn-Sham orbitals, whereas $a, b, c, \ldots$ denote virtual orbitals. The superscript $\sigma$ denotes the different spins $\sigma=\alpha, \beta$. The PT2 amplitudes are collected in matrices $\mathbf{t}^{i_{\sigma} j_{\sigma^{\prime}}}$ with the elements, 


$$
t_{a_{\sigma} b_{\sigma^{\prime}}}^{i_{\sigma} j_{\sigma^{\prime}}}=\bar{K}_{a_{\sigma} b_{\sigma^{\prime}}}^{i_{\sigma} j_{\sigma^{\prime}}}\left(\epsilon_{i}^{\sigma}+\epsilon_{j}^{\sigma^{\prime}}-\epsilon_{a}^{\sigma}-\epsilon_{b}^{\sigma^{\prime}}\right)^{-1}
$$

where the orbitals are assumed to be canoncical with orbital energies $\epsilon_{p}^{\sigma}$. The exchange operator matrices $K_{a_{\sigma} b_{\sigma^{\prime}}}^{i_{\sigma} j_{\sigma^{\prime}}}$ and the antisymmetrized exchange integrals $\bar{K}_{a_{\sigma} b_{\sigma^{\prime}}}^{i_{\sigma} j_{\sigma^{\prime}}}$ are defined as,

$$
\begin{aligned}
K_{a_{\sigma} b_{\sigma^{\prime}}}^{i_{\sigma} j_{\sigma^{\prime}}} & =\left(i_{\sigma} a_{\sigma} \mid j_{\sigma^{\prime}} b_{\sigma^{\prime}}\right) \\
\bar{K}_{a_{\sigma} b_{\sigma^{\prime}}}^{i} i_{\sigma} j_{\sigma^{\prime}} & =\left(i_{\sigma} a_{\sigma} \mid j_{\sigma^{\prime}} b_{\sigma^{\prime}}\right)-\delta_{\sigma \sigma^{\prime}}\left(i_{\sigma} b_{\sigma} \mid j_{\sigma} a_{\sigma}\right) .
\end{aligned}
$$

In order to obtain the occupied-virtual block of the relaxed difference density, a single set of CP-SCF equations (Z-vector equations) [61] needs to be solved (for a detailed description, see ref. [56] and references therein). In order to obtain the relaxed density we first define the Lagrangian:

$$
\begin{aligned}
L_{a i}^{\sigma}= & R^{\sigma}\left(\mathbf{D}^{\prime}\right)_{a i}+2 \sum_{j_{\sigma} b_{\sigma} c_{\sigma}}\left(a_{\sigma} c_{\sigma} \mid j_{\sigma} b_{\sigma}\right) t_{c_{\sigma} b_{\sigma}}^{i_{\sigma} j_{\sigma}}-2 \sum_{j_{\sigma} k_{\sigma} b_{\sigma}}\left(k_{\sigma} i_{\sigma} \mid j_{\sigma} b_{\sigma}\right) t_{a_{\sigma} b_{\sigma}}^{k_{\sigma} j_{\sigma}} \\
& +2 \sum_{j_{\sigma^{\prime} b_{\sigma^{\prime}} c_{\sigma}}}\left(a_{\sigma} c_{\sigma} \mid j_{\sigma^{\prime}} b_{\sigma^{\prime}}\right) t_{b_{\sigma^{\prime}} c_{\sigma} i_{\sigma}}^{j_{\sigma^{\prime}}}-2 \sum_{j_{\sigma^{\prime}} k_{\sigma} b_{\sigma^{\prime}}}\left(k_{\sigma} i_{\sigma} \mid j_{\sigma^{\prime}} b_{\sigma^{\prime}}\right) t_{b_{\sigma^{\prime}} a_{\sigma}}^{j_{\sigma^{\prime}} k_{\sigma}} .
\end{aligned}
$$

The matrix elements of the response operator $R^{\sigma}\left(\mathbf{D}^{\prime}\right)$ in the atomic orbital (AO) basis are given by

with

$$
\begin{aligned}
R^{\sigma}\left(\mathbf{D}^{\prime}\right)_{\mu \nu}= & \sum_{\kappa \tau} 2 D_{\kappa \tau}^{\prime}(\mu \nu \mid \kappa \tau)-D_{\kappa \tau}^{\prime \sigma}[(\mu \kappa \mid \nu \tau)+(\nu \kappa \mid \mu \tau)] \\
& -\sum_{\zeta} \int\left[\frac{\delta^{2} f}{\delta \rho_{\sigma} \delta \zeta} \zeta\left(\mathbf{D}^{\prime}\right)\left(\varphi_{\mu} \varphi_{\nu}\right)\right. \\
& +\left(2 \frac{\delta^{2} f}{\delta \gamma_{\sigma \sigma} \delta \zeta} \vec{\nabla} \rho_{\mathbf{P}}^{\sigma}+\frac{\delta^{2} f}{\delta \gamma_{\sigma \sigma^{\prime}} \delta \zeta} \vec{\nabla} \rho_{\mathbf{P}}^{\sigma^{\prime}}\right) \zeta\left(\mathbf{D}^{\prime}\right) \vec{\nabla}\left(\varphi_{\mu} \varphi_{\nu}\right) \\
& \left.+\left(2 \frac{\delta f}{\delta \gamma_{\sigma \sigma}} \vec{\nabla} \rho_{\mathbf{D}^{\prime}}^{\sigma}+\frac{\delta f}{\delta \gamma_{\sigma \sigma^{\prime}}} \vec{\nabla} \rho_{\mathbf{D}^{\prime}}^{\sigma^{\prime}}\right) \vec{\nabla}\left(\varphi_{\mu} \varphi_{\nu}\right)\right] d \vec{r}
\end{aligned}
$$

$$
\zeta\left(\mathbf{D}^{\prime}\right)=\rho_{\mathbf{D}^{\prime}}^{\alpha}, \rho_{\mathbf{D}^{\prime}}^{\beta}, \gamma_{\alpha \alpha}\left(\mathbf{D}^{\prime}\right), \gamma_{\beta \beta}\left(\mathbf{D}^{\prime}\right), \gamma_{\alpha \beta}\left(\mathbf{D}^{\prime}\right)
$$




$$
\gamma_{\alpha \alpha}\left(\mathbf{D}^{\prime}\right)=2 \vec{\nabla} \rho_{\mathbf{D}^{\prime}}^{\alpha} \rho_{\mathbf{P}}^{\alpha}
$$

with

$$
\begin{aligned}
\rho_{\mathbf{D}^{\prime}}^{\alpha}(\vec{r}) & =\sum_{\mu \nu} D_{\mu \nu}^{\alpha \alpha} \varphi_{\mu}(\vec{r}) \varphi_{\nu}(\vec{r}) \\
\rho_{\mathbf{P}}^{\alpha}(\vec{r}) & =\sum_{\mu \nu} P_{\mu \nu}^{\alpha} \varphi_{\mu}(\vec{r}) \varphi_{\nu}(\vec{r}) .
\end{aligned}
$$

The CP-SCF equations need now to be solved for the elements of the $\mathbf{Z}$-vector,

$$
\left(\epsilon_{a}^{\sigma}-\epsilon_{i}^{\sigma}\right) Z_{a i}^{\sigma}+R^{\sigma}(\mathbf{Z})_{a i}=-L_{a i}^{\sigma} .
$$

The solution then defines the occupied-virtual block of the relaxed difference density, which is given by,

$$
\mathbf{D}^{\sigma}=\mathbf{D}^{\prime \sigma}+\mathbf{Z}^{\sigma} .
$$

This final density is used in the HFC calculations.

\section{$3 \quad$ Results and Analysis}

\subsection{Computational Details}

In order to test the performance of the new methods, the hyperfine coupling constants for a series of small radicals and transition metal complexes were computed and compared to experimental data. The ligand structures of the transition metal complexes together with the abbreviations used, are shown in Figure (1). All calculations were carried out using the 
ORCA program package. [62] The geometries of the transition metal complexes studied in this work were optimized at the meta-GGA level of DFT, employing the TPSS [54] functional in combination with a basis set of polarized triple- $\zeta$ quality for all atoms (TZVP [63]). The smaller systems were optimized on the coupled cluster level including single and double excitations with a perturbative estimate of triple excitations ( $\operatorname{CCSD}(\mathrm{T})$ ). [64] Dunning's cc-pVTZ basis set was chosen for these purposes. [65] In the case of the $\mathrm{OH}, \mathrm{NO}$ and $\mathrm{NH}_{2}$ radicals experimental structures were used. Furthermore, for a subset of the test set we optimized structures with the same functional with which the HFCs are computed. In this case, the TZVP basis was chosen again and the resolution of the identity technique was employed only for the optimizations. [66] We have chosen tight SCF and geometry convergence criteria for these purposes.

For the study of the hyperfine coupling constants single point calculations were performed on the optimized structures employing five different density functionals: (a) BP86 [40,50], (b) B3LYP [40-42], (c) TPSS [54], (d) TPSSh [67] and (e) B2PLYP [55]. The functionals BP86 and B3LYP were chosen as reference in order to benchmark the results provided by the meta-GGA and double hybrid functionals.

Barone's triple- $\zeta$ EPR-III [68] basis set was employed for the calculation of the hyperfine coupling constants with the exception of the elements $\mathrm{Al}, \mathrm{S}, \mathrm{Cl}$ and $\mathrm{Si}$ for which Kutzelniggs IGLO-III [69] basis set was used. An accurate triply polarized basis set, CP(PPP), was applied for the transition metal atoms. [70] For the perturbation theory based functional B2PLYP relaxed densities have been utilized throughout but no approximation such like density fitting has been employed.

The convergence criteria for the energy change was chosen to be $10^{-8} E_{h}$ throughout.

In the case of transition metal complexes, for which relativistic effects are not negligible, the spin-orbit contributions to the hyperfine coupling constant are computed via the spinorbit mean field (SOMF) approach. [57] In the implementation of ref [71] which is equivalent to the earlier formulation of Berning et al. [72] the isotropic and dipolar hyperfine coupling contributions are corrected utilizing the zero order regular approximation (ZORA), [46,73,74] 
which is implemented in ORCA according to van Wüllen. [75] The values for $\mathrm{A}_{\text {iso }}$ and $\mathrm{A}_{\text {dip }}$ calculated with the double hybrid functional B2PLYP are corrected at the SCF level, because the scaled ZORA densities can not yet be calculated for MP2 relaxed or unrelaxed densities.

$$
\begin{array}{r}
\Delta A_{S C F}^{(A ; c)}=A_{Z O R A}^{(A ; c)}-A_{S C F}^{(A ; c)} \\
A_{B 2 P L Y P}^{(A ; c)}=A_{r e l}^{(A ; c)}+\Delta A_{S C F}^{(A ; c)}
\end{array}
$$

The ZORA correction at the SCF level is added to the hyperfine coupling constants calculated with relaxed densities, eq. (23). The correction of the dipolar hyperfine coupling constant is straightforward.

\section{[Figure 1 about here.]}

In order to avoid any possible ambiguity Table 1 lists the isotopes, nuclear spins and scaled nuclear g-values used in the calculations.

[Table 1 about here.]

\subsection{Numerical results}

In this section the different DFT functionals are applied to a test set of few well-studied first row transition metal complexes and to a collection of small radicals.

\subsubsection{Radicals}

[Table 2 about here.]

[Table 3 about here.] 
[Table 4 about here.]

[Table 5 about here.]

[Table 6 about here.]

In Table 2 the results of the calculation of the hyperfine coupling constants for a series of $\mathrm{S}=1 / 2$ diatomics are given. The BP86 GGA performs best for the ${ }^{14} \mathrm{~N}$ nucleus in the CN molecule and for the ${ }^{27} \mathrm{Al} \mathrm{HFC} \mathrm{in} \mathrm{AlO}$ that is, however, still predicted far off the experimental value. The B3LYP hybrid functional provides the best results for the ${ }^{13} \mathrm{C}$ nucleus in $\mathrm{CN}$ and $\mathrm{CO}^{+}$as well as for the ${ }^{25} \mathrm{Mg}$ HFC in MgF. However, neither the HFCs for ${ }^{11} \mathrm{~B}$ in $\mathrm{BO}$ nor the ones for ${ }^{27} \mathrm{Al}$ in $\mathrm{AlO}$ are sufficiently accurately described. Nevertheless, on average B3LYP is the most accurate of the well established functionals for the calculation of the HFCs of the diatomics in the test set.

The TPSS meta-GGA can not reproduce the HFCs for MgF, but is otherwise in good agreement with the results provided by the reference functionals with a slight tendency for underestimation of the HFCs. This points to a still underestimated spin-polarization with this functional. A clear improvement over TPSS is offered by its hybrid variant TPSSh. There are some notable exceptions to this general trend which include the ${ }^{14} \mathrm{~N}$ HFC in $\mathrm{CN}$ and the ${ }^{17} \mathrm{O} \mathrm{HFC}$ in $\mathrm{CO}^{+}$.

The double hybrid functional B2PLYP fails badly for the CN molecule (a case with strong spin contamination caused by the large fraction of HF exchange), but outperforms the reference functionals for ${ }^{13} \mathrm{C}$ in $\mathrm{CO}^{+}$and for ${ }^{17} \mathrm{~F}$ in $\mathrm{MgF}$. With the exception of ${ }^{25} \mathrm{Mg}$ in $\mathrm{MgF}$ B2PLYP tends to slightly exaggerate the magnitude of $\mathrm{A}_{\text {dip }}$.

Table 3 represents the results of $\mathrm{HFC}$ calculations for $\mathrm{S} \geq 1 / 2$ systems. It is evident that the BP86 GGA is not a good choice for these systems. The magnitude of $\mathrm{A}_{i s o}$ is significantly underestimated in most cases. The B3LYP functional performs usually well for this test set, but is in some cases outperformed by TPSSh and B2PLYP. The TPSS shows a major improvement over the BP86 functional, but can not reach the accuracy of the B3LYP hybrid 
functional. The B2PLYP DHDF is certainly a competitive alternative to B3LYP within this test set. An exception is the orbitally degenerate NO molecule for which the perturbative correction is not appropriate. For less pathological cases B2PLYP performs as least as well as B3LYP and surpasses its accuracy in the cases of $\mathrm{OH}, \mathrm{NH}$ and $\mathrm{O}_{2}$.

In Tables 4, 5 and 6 the calculated HFCs for a variety of small polyatomic systems are listed. The HFCs of $\mathrm{SiH}_{3}$ and $\mathrm{NF}_{3}^{+}$can not be predicted by any of the employed functionals. Besides these disturbing cases, the TPSS functional seems to be a good choice for the evaluation of hyperfine couplings in the given series. The results provided by TPSS are in general inferior to those provided by its hybrid derivative, but regarding the cost to accuracy ratio, TPSS still presents a good alternative to the hybrid functionals. The results obtained with B2PLYP are in excellent agreement with those provided by the reference functionals.

The analysis of the average errors in Table 6 shows that B2PLYP has an excellent mean error of close to zero but the mean absolute error is slightly worse than B3LYP and TPSSh. In general, all employed functionals except BP86 perform in the same range. The mean absolute errors of B3LYP and TPSSh are very similar and no functional shows a significant improvement over B3LYP. If computational cost is an issue, the TPSS functional is a reasonable choice since it is clearly superior to BP86 but can be evaluated at only slightly higher computational cost than standard GGAs and significantly faster than hybrid or double hybrid functionals.

We conclude that for the HFCs of the small molecules studied here, DFT offers generally excellent performance. The results could probably be further improved by vibrational averaging but this has not been attempted in the present study. 


\subsubsection{Transition metal complexes}

[Table 7 about here.]

[Table 8 about here.]

The calculated HFCs for a series of transition metal ions in different ligand environments are listed in Tables 7, 8. Here the situation is quite different from the case of small main group radicals since B2PLYP clearly outperforms all reference functionals. The only unexpected failure provided by the B2PLYP functional occurs for the HFC of $\left[\mathrm{Mn}(\mathrm{CO})_{5}\right]$ where it fails badly. Neglecting this outlier together with $\mathrm{MnO}_{3}$ within the error statistics of B2PLYP yields a mean absolute error for $\mathrm{A}_{i s o}$ of $22.3 \mathrm{MHz}$ which is almost 1.5 times as good as the next best functional TPSSh.

The hybrid meta-GGA functional TPSSh presents a clear improvement over B3LYP in most cases and this is reflected in the statistics as well. TPSSh can predict the HFCs of $\mathrm{MnO}_{3}$ satisfactorily, whereas B3LYP fails badly in this case. In the remaining cases both functionals show similar performance. As found for main group radicals, TPSS outperforms BP86, but does not reach the accuracy of its hybrid derivative. On the positive side, TPSS does not provide any disastrous failures and reproduces the experimental data fairly well.

We were curious whether the inclusion of scalar relativistic effects would further improve the B2PLYP values. We have consequently redone the B2PLYP calculations in the framework of the zero'th order regular approximation (ZORA) in its one-component form. The ZORA formalism is an approximation to the relativistic Dirac equation which transforms the original four-component Hamiltonian into a two-component form. [73] Density functional calculations within the ZORA formalism show only differences in the kinetic energy part of the SCF equations compared to usual Kohn-Sham theory. The ZORA kinetic energy operator depends implicitly on the Kohn-Sham orbitals through the Coulomb and exchangecorrelation potentials. [75] In the ZORA formalism, the calculation of magnetic properties is particularly straightforward as was first shown by van Lenthe et al. [46] In the present case, it was only possible to compute the scalar relativistic corrections to all parts of the HFC at 


\subsubsection{Ligand Superhyperfine structure}

[Table 9 about here.]

Table 9 presents the results of the calculated HFCs for selected ligand nuclei for which experimental data exist. The TPSSh hybrid functional performs generally best for all predicted HFCs. The results provided by the BP86 GGA are also in good agreement with the experimental references. The TPSS meta-GGA outperforms B3LYP as well except in the case of ${ }^{33} \mathrm{~S}$ in $\left[\mathrm{Ni}(\mathrm{mnt})_{2}\right]^{-}$. B2PLYP apparently gives an erroneous electronic structure description for $\left[\mathrm{Ni}(\mathrm{CO})_{3} \mathrm{H}\right]$ and consequently fails to provide a reasonable estimate of the ${ }^{1} \mathrm{H}$ HFC. The analysis of average errors in in Table 9 demonstrates a systematic underestimation of the ligand HFCs for both hybrid functionals. In this comparison B2PLYP yields the lowest average error in the total as well as in the isotropic HFCCS and the systematic bias is very small. The excellent results obtained with the BP86 functional are probably influenced to a certain extent by error cancellation as has been analyzed previously. [15]

It is instructive to analyze the B2PLYP densities somewhat further. As described above, in this method, there are three types of densities available: (a) the SCF densities, (b) the unrelaxed densities and (c) the relaxed densities. The relaxed densities are the most consistent ones since they accurately describe the linear response of the B2PLYP total energy with respect to the hyperfine perturbation. It is well-known of course, and has been analyzed many times that GGA functionals tend to exaggerate covalent bonding and transfer too much spin to the ligand while Hartree-Fock is on the opposite extreme and predicts metal-ligand bonds that are far too ionic. $[47,48,108]$ 
Solomon and co-workers have suggested to use an elevated amount of $38 \%$ exact exchange to be mixed into the BP86 functional in order to obtain better metal-ligand bonding descriptions. [48] Hence, the 53\% present in B2PLYP should lead to exaggerated metal spin populations at the SCF level. Indeed, this is found. For the the example of $\mathrm{Cu}\left(\mathrm{NH}_{3}\right)_{4}^{2+}$ the SCF spin-population at the central copper is $76 \%$ which is certainly too high since the analysis of EPR experiments indicates that values around $65 \%$ are more reasonable. Indeed, the correlation contribution to the relaxed densities leads to a fairly substantial change in the predicted spin populations since the relaxed density displays a Mulliken spin population of $63 \%$. This shows that the new double hybrid functionals actually incorporate correct and important physics in their design. This is, of course, also reflected in the calculated metaland ligand hyperfine couplings. Thus, the isotropic ${ }^{14} \mathrm{~N}-\mathrm{HFC}$ is predicted to be $28.5 \mathrm{MHz}$ with the unrelaxed densities and $37.2 \mathrm{MHz}$ with the relaxed densities the latter of which is in excellent agreement with the experimental estimates (a rigorous comparison is of course not possible since spin populations are not quantum mechanical observables). The fact that the high accuracy does not always hold for B2PLYP will be discussed in the concluding section.

[Figure 2 about here.]

[Figure 3 about here.]

\subsubsection{Geometry dependence of the predicted hyperfine couplings}

Based on the comments of a referee we have repeated some of the calculations in a way where the same functional was used for the geometry optimization and the property prediction. The results of these calculations are collected below in Table 10.

[Table 10 about here.]

As becomes evident from table 10, the magnitude of the HFCs is increased if the structure optimization and the HFC calculation are performed with the same functional. However, this does not consistently yield improved predictions. For example, in the case of $\left[\mathrm{Cu}\left(\mathrm{NH}_{3}\right)_{4}\right]^{2+}$ 


\section{Concluding Remarks}

In this work hyperfine couplings for a series of small radicals and for a variety of transition metal complexes were studied computationally using different modern density functionals. The trends observed for the TPSS meta-GGA agree well with the results in ref. [34]. TPSS represents major improvements over BP86 but can not reach the accuracy of the hybrid functionals for the prediction of HFCs. Compared to the meta-GGAs tested previously by Arbuznikov et al., [33] TPSS is to be preferred. The hybrid variant, TPSSh, is a clear improvement over TPSS and represents an attractive alternative to the widely used B3LYP hybrid functional for HFC calculations. Particularly, in the prediction of transition metal HFC TPSSh offers advantages over B3LYP.

The B2PLYP double hybrid functional represents a special case. For many systems, the additional physics incorporated into the double hybrid functionals leads to improvements 
in the results. This is particularly true for the transition metal HFCs. Here, the elevated fraction of HF exchange leads to an increase in spin-polarization that in turn leads to larger HFCs. However, increasing the fraction of HF exchange to about $50 \%$ alone would lead to an overshooting that is, however, partially damped by the additional corrections provided by the perturbative correlation correction that is quite important for obtaining accurate results. Thus, it is an important issue to correlate the core level electrons in HFC calculations with double hybrid functionals and a more detailed study of this issue seems to be warranted. However, the improvements offered by double hybrid functionals come at the price of a somewhat reduced stability. In all likelihood this stems from the second-order perturbation approach in combination with the elevated fraction of HF exchange present in these functionals. Since both, UHF as well as UMP2 are very inaccurate and partially erratic for HFC calculations this result had probably to be expected. One case, where the elevated fraction of $\mathrm{HF}$ exchange leads to desastrous results is $\mathrm{MnO}_{3}$, as has been analyzed in some detail in the context of hybrid density functional theory by Munzarova and Kaupp. [35]. Nevertheless, B2PLYP is certainly much more stable than either UHF or UMP2 (even in the presence of significant spin contamination) and, except for electronically very difficult situations, provides excellent predictions for HFCs.

In future work the consistent incorporation of scalar relativistic effects and the implementation of response properties on the basis of double hybrid functionals should be pursued.

Unfortunately, the present work does still not offer a general answer to the question of which density functional should generally be used for HFC calculations since the "best" functional appears to be system dependent. The well established B3LYP functional is, on average, still an excellent choice which is, however, rivaled by the TPSSh hybrid functional. B2PLYP is a much more stable method than either UHF or UMP2 and except for electronically very difficult systems it provides HFC predictions of excellent quality. If computational cost is a serious issue the use of the TPSS meta-GGA is clearly to be preferred over BP86. 


\section{Acknowledgments}

This paper is dedicated to the memory of Arthur Schweiger, a great pioneer of EPR spectroscopy and a noble and generous man. We appreciate the financial support by the DFG priority program 1137, the SFB 663, the SFB 624 and the university of Bonn. Mr. Jens Mekelburger and Dr. Frank Wennmohs are gratefully acknowledged for technical support.

\section{References}

[1] Schweiger, A.; Jeschke, G. Principles of Pulse Electron Paramagnetic Resonance; Oxford University Press: Oxford, 2001.

[2] Kababya, S.; Nelson, J.; Calle, C.; Neese, F.; Goldfarb, D. J. Am. Chem. Soc. 2006, $128,2017$.

[3] Kaupp, M.; Malkin, V.; Bühl, M. The Quantum Chemical Calculation of NMR and EPR Properties; Wiley-VCH: Heidelberg, 2004.

[4] Neese, F. In Electron Paramagnetic Resonance, Vol. 20; Gilbert, B. C.; Davies, M. J.; Murphy, D. M., Eds.; The Royal Society of Chemistry: Cambridge, 2007.

[5] Neese, F. In Biological Magnetic Resonance; Hanson, G., Ed.; Kluwer AcademicPlenum Press: New York, 2007, in press.

[6] McConnell, H. M. J. Chem. Phys. 1956, 24, 764.

[7] McConnell, H. M.; Chesnut, D. B. J. Chem. Phys. 1958, 28, 107.

[8] McConnell, H. M. J. Chem. Phys. 1958, 28, 1188.

[9] Weissman, S. I.; Paul, J. T. D. E.; Pake, G. E. J. Chem. Phys. 1953, 21, 2227.

[10] Weissman, S. I. J. Chem. Phys. 1955, 25, 890.

[11] Tuttle, T. R., Jr.; Ward, R. L.; Weissman, S. I. J. Chem. Phys. 1956, 25, 189. 
[12] Tuttle, T. R., Jr.; Weissman, S. I. J. Chem. Phys. 1956, 25, 189.

[13] Abragam, A.; Pryce, M. H. L. Proc. R. Soc. London, Ser. A 1951, 205, 135.

[14] Griffith, J. S. The Theory of Transition-Metal Ions; Cambridge University Press: Cambridge, 1961.

[15] Neese, F. J. Phys. Chem. A 2001, 105, 4290.

[16] Carrington, A.; McLachlan, A. D. Introduction To Magentic Resonance; Chapman and Hall: London, 1967.

[17] Fermi, E. Z. Physik 1930, 60, 320.

[18] Rassolov, V. A.; Chipman, D. M. J. Chem. Phys. 1996, 105, 1470.

[19] Rassolov, V. A.; Chipman, D. M. J. Chem. Phys. 1996, 105, 1479.

[20] Chipman, D. M.; Rassolov, V. A. J. Chem. Phys. 1997, 107, 5488.

[21] Kutzelnigg, W. Theoret. Chim. Acta 1988, 73, 173.

[22] Hameka, H. F.; Turner, A. G. J. Magn. Reson. 1985, 64, 66.

[23] Chipman, D. M. Theoret. Chim. Acta 1992, 82, 93.

[24] Gauld, J. W.; Eriksson, L. A.; Radom, L. J. Phys. Chem. A 1997, 101, 1352.

[25] Wetmore, S. D.; Eriksson, L. A.; Boyd, R. J. J. Chem. Phys. 1998, 109, 9451.

[26] Improta, R.; Barone, V. Chem. Rev. 2004, 104, 1231.

[27] Carmichael, I. J. Phys. Chem. 1991, 95, 108.

[28] Carmichael, I. J. Phys. Chem. A 1997, 101, 4633.

[29] Suter, H. U.; Engels, B. J. Chem. Phys. 1994, 100, 2936.

[30] Ishii, N.; Shimizu, T. Phys. Rev. A 1993, 48, 1691. 
[31] Engels, B.; Eriksson, L. A.; Lunell, S. . In Advances in Quantum Chemistry, Vol. 27; Academic Press Inc.: 1996.

[32] Barone, V.; Adamo, C.; Russo, N. Chem. Phys. Lett. 1993, 212, 5.

[33] Arbuznikov, A. V.; Kaupp, M.; Malkin, V. G.; Reviakine, R.; Malkina, O. L. Phys. Chem. Chem. Phys. 2002, 4, 5467.

[34] Rogowska, A.; Kuhl, S.; Schneider, R.; Walcarius, A.; Champagne, B. Phys. Chem. Chem. Phys. 2007, 8, 828.

[35] Munzarova, M.; Kaupp, M. J. Phys. Chem. A 1999, 103, 9966.

[36] Munzarova, M.; Kubáček, P.; Kaupp, M. J. Am. Chem. Soc. 2000, 122, 11900.

[37] Kacprzak, S.; Kaupp, M. J. Phys. Chem. A 2004, 108, 2464.

[38] Drew, S. C.; Young, C. G.; Hanson, G. R. 2007, 46, 2388.

[39] de Almeida, K. J.; Rinkevicius, Z.; Hugosson, H. W.; Ferreira, A. C.; Ågren, H. Chem. Phys. 2007, 332, 176.

[40] Becke, A. D. Phys. Rev. A 1988, 38, 3098.

[41] Becke, A. D. J. Chem. Phys. 1993, 98, 5648.

[42] Lee, C.; Yang, W.; Parr, R. G. Phys. Rev. B 1988, 37, 785.

[43] Barone, V.; Polimeno, A. Phys. Chem. Chem. Phys. 2006, 8, 4609.

[44] Asher, J. R.; Kaupp, M. ChemPhysChem 2007, 8, 69.

[45] Neese, F. Magn. Reson. Chem. 2004, 42, 187.

[46] van Lenthe, E.; van der Avoird, A.; Wormer, P. E. S. J. Chem. Phys. 1998, 108, 4783.

[47] Neese, F. J. Chem. Phys. 2003, 118, 3939.

[48] Szilagyi, R. K.; Metz, M.; Solomon, E. I. J. Phys. Chem. A 2002, 106, 2994. 
[49] Sinnecker, S.; Slep, L.; Bill, E.; Neese, F. Inorg. Chem. 2005, 44, 2245.

[50] Perdew, J. P. Phys. Rev. B 1986, 33, 8822.

[51] Perdew, J. P.; Burke, K.; Ernzerhof, M. Phys. Rev. Lett. 1996, 77, 3865.

[52] Becke, A. D. J. Chem. Phys. 1993, 98, 1372.

[53] Perdew, J. P.; Kurth, S.; Zupan, A.; Blaha, P. Phys. Rev. Lett. 1999, 82, 2544.

[54] Tao, J.; Perdew, J. P.; N.Staroverov, V.; Scuseria, G. E. Phys. Rev. Lett. 2003, 91, 146401.

[55] Grimme, S. J. Chem. Phys. 2006, 124, 034108.

[56] Neese, F.; Schwabe, T.; Grimme, S. J. Chem. Phys. 2007, 126, 124115.

[57] Hess, B. A.; Marian, C. M.; Wahlgren, U.; Gropen, O. 1996, 251, 365.

[58] Salter, E. A.; Trucks, G. W.; Fitzgerald, G.; Bartlett, R. J. Chem. Phys. Lett. 1987, $141,61$.

[59] Trucks, G. W.; Salter, E. A.; Sosa, C.; Bartlett, R. J. Chem. Phys. Lett. 1988, 147, 359.

[60] Trucks, G. W.; Salter, E. A.; Noga, J.; Bartlett, R. J. Chem. Phys. Lett. 1988, 150, 37.

[61] Handy, N. C.; Schaefer, H. F. J. Chem. Phys. 1984, 81, 5031.

[62] Neese, F. ORCA - an ab initio, density functional and semiempirical program package, Version 2.6-3; Institute for physical and theoretical chemistry: Bonn, Germany, 2006.

[63] Schäfer, A.; Huber, C.; Ahlrichs, R. J. Chem. Phys. 1994, 100, 5829.

[64] Raghavachari, K.; Trucks, G. W.; Pople, J. A.; Head-Gordon, M. Chem. Phys. Lett. 1989, 157, 479 .

[65] Dunning, T. H. J. J. Chem. Phys. 1989, 90, 1007. 
[66] Eichkorn, K.; Treutler, O.; Öhm, H.; Häser, M.; Ahlrichs, R. Chem. Phys. Lett. 1995, 240, 283.

[67] Staroverov, V. N.; Scuseria, G. E.; Tao, J.; Perdew, J. P. J. Chem. Phys. 2003, 119, 12129.

[68] Rega, N.; Cossi, M.; Barone, V. J. J. Chem. Phys. 1996, 105, 11060.

[69] Kutzelnigg, W.; Fleischer, U.; Schindler, M. . In NMR-Basic Principles and Progress, Vol. 213; Springer Verlag: Heidelberg, 1991.

[70] Neese, F. Inorg. Chim. Acta 2002, 337,.

[71] Neese, F. J. Chem. Phys. 2005, 122, 034107.

[72] Berning, A.; Schweizer, M.; Werner, H. J.; Knowles, P. J.; Palmieri, P. Mol. Phys. 2000, 98, 1823.

[73] van Lenthe, E.; Baerends, E. J.; Snijders, J. G. J. Chem. Phys. 1993, 99, 4597.

[74] Heully, J. L.; Lindgren, I.; Lindroth, E.; Lundquist, S.; Mårtensson, A. M. J. Phys. $B$ 1986, 19, 2799.

[75] van Wüllen, C. J. Chem. Phys. 1998, 109, 392.

[76] Easley, W. C.; W. Weltner, J. J. Chem. Phys. 1970, 52, 197.

[77] L. B. Knight, J.; Steadman, J.; Miller, P. K.; Bowman, D. E.; Davidson, E. R.; Feller, D. J. Chem. Phys. 1984, 80, 4593.

[78] L. B. Knight, J.; Wise, M. B.; Davidson, E. R.; McMurchie, L. E. J. Chem. Phys. 1982, 76, 126.

[79] L. B. Knight, J.; W. Weltner, J. J. Chem. Phys. 1971, 55, 5066.

[80] Feller, D.; Davidson, E. R. . In Modern Density Functional Theory: A Tool for Chemistry; Maksić, Z. B., Ed.; Springer Verlag: 1991. 
[81] L. B. Knight, J.; Wise, M. B.; Childers, A. G.; Davidson, E. R.; Daasch, W. R. J. Chem. Phys. 1980, 73, 4198.

[82] J. M. Brom, J.; W. Weltner, J. J. Chem. Phys. 1972, 57, 3379.

[83] W. Weltner, J. Magnetic Atoms and Molecules; Dover: New York, 1983.

[84] Gazzoli, G.; Espositi, C. D.; Favero, P. G.; Severi, G. Nuovo Cimento 1981, B 61, 243.

[85] Malkin, V. G.; Malkina, O. L.; Eriksson, L. A.; Salahub, D. R. . In Modern Density Functional Theory: A Tool for Chemistry; Seminario, J. M.; Politzer, P., Eds.; Elsevier Science: 1995.

[86] Eriksson, L. A. . In Encyclopedia of Computational Chemistry; v. R. Schleyer, P., Ed.; Wiley VCH: Chichester, 1997.

[87] Chipman, D. M. J. Chem. Phys. 1983, 78, 3112.

[88] Foner, S. N.; Cochran, E. L.; Bowers, V. A.; Jen, C. K. Phys. Rev. Lett. 1958, 1, 91.

[89] Childs, J.; Steimle, T. C. J. Phys. Chem. 1988, 88, 6168.

[90] Varberg, D.; Field, R. W.; Merer, A. J. J. Chem. Phys. 1991, 95, 1563.

[91] Namiki, K.; Saito, S. J. Chem. Phys. 1997, 107, 8848.

[92] DeVore, C.; Weltner, W., Jr. J. Chem. Phys. 1978, 68, 3522.

[93] DeVore, C.; Weltner, W., Jr. J. Am. Chem. Soc. 1977, 99, 4700.

[94] Ferrante, F.; Wilkerson, J. L.; Graham, W. R. M.; Weltner, W., Jr. J. Chem. Phys. 1977, 67, 5904 .

[95] Scholl, H. J.; Hüttermann, J. J. Phys. Chem. 1992, 96, 9684.

[96] Keijzers, C. P.; Snaathorst, D. Chem. Phys. Lett. 1980, 69, 348.

[97] Maki, A. H.; McGarvey, B. R. J. Chem. Phys. 1958, 29, 31. 
[98] Rollmann, L. D.; Chan, S. I. . In Electron Spin Resonance of Metal Complexes; Yen, T. F., Ed.; Hilger: London, 1969.

[99] Morton, J. R.; Preston, K. F. J. Chem. Phys. 1984, 81, 5775.

[100] Schmitt, R. D.; Maki, A. H. J. Am. Chem. Soc. 1968, 90, 2288.

[101] Lionel, T.; Morton, J. R.; Preston, K. F. J. Chem. Phys. 1982, 76, 234.

[102] Howard, J. A.; Morton, J. R.; Preston, K. F. Chem. Phys. Lett. 1981, 83, 1226.

[103] Upreti, G. C. J. Chem. Phys. 1974, 13,.

[104] Fairhurst, S. A.; Morton, J. R.; Preston, K. F. Chem. Phys. Lett. 1984, 104, 112.

[105] McGarvey, B. R. Transition Metal Chemistry 1966, 3, 89.

[106] Atherton, N. M.; Shackleton, J. F. Mol. Phys. 1980, 39, 1471.

[107] Baute, D.; Goldfarb, D. J. Phys. Chem. A 2005, 109, 7868.

[108] Neese, F.; Solomon, E. I. . In Magnetoscience - From Molecules to Materials, Vol. 4; Miller, J. S.; Drillon, M., Eds.; Wiley-VCH Verlag: Weinheim, 2003.

[109] Bühl, M.; Kabrede, H. J. Chem. Theory Comput. 2006, 2, 1282. 


\section{List of Figures}

1 Structures of the ligands used in this study. . . . . . . . . . . . . . . 27

2 Graphical representation of the mean error for the calculation of hyperfine coupling constants depending on the functional and the system. . . . . . . . . . 28

3 Graphical representation of the mean absolute error for the calculation of hyperfine coupling constants depending on the functional and the system. . . . . . . . . . . 29 


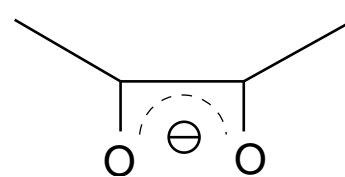

acac

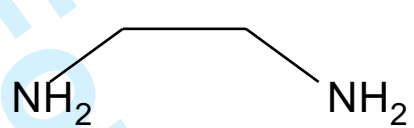

en

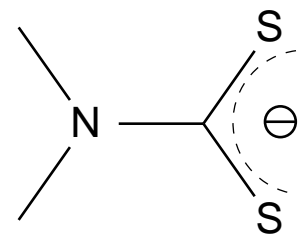

dtc

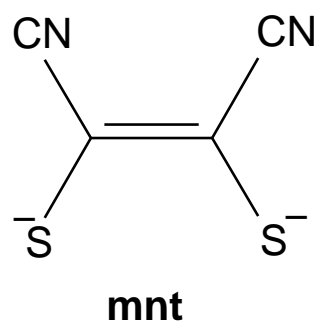

Figure 1: Structures of the ligands used in this study. 

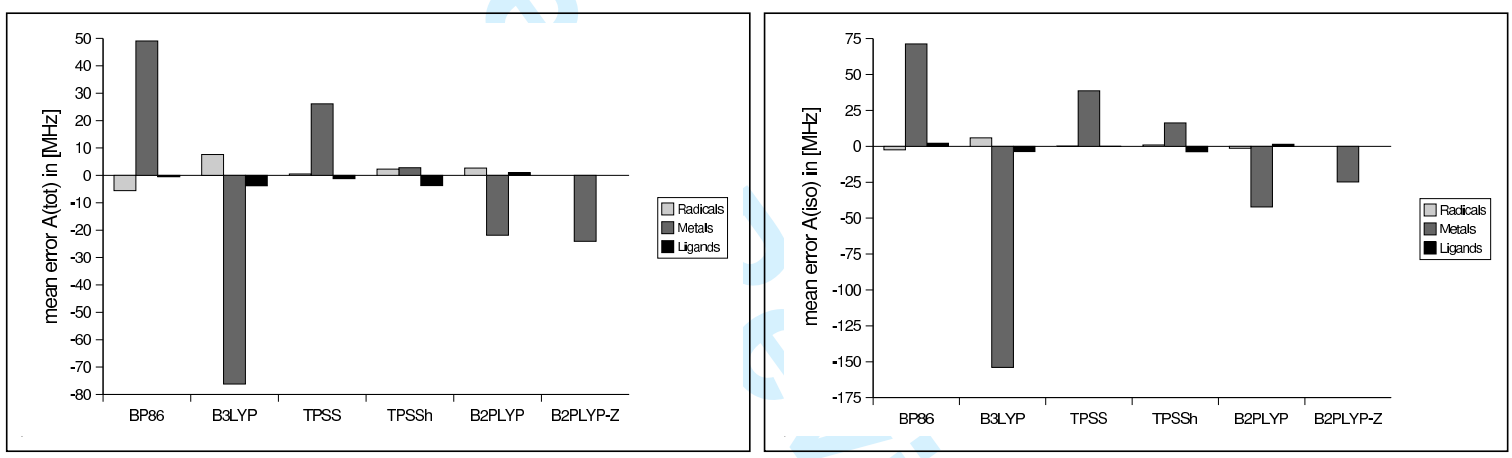

Figure 2: Graphical representation of the mean error for the calculation of hyperfine coupling constants depending on the functional and the system. 

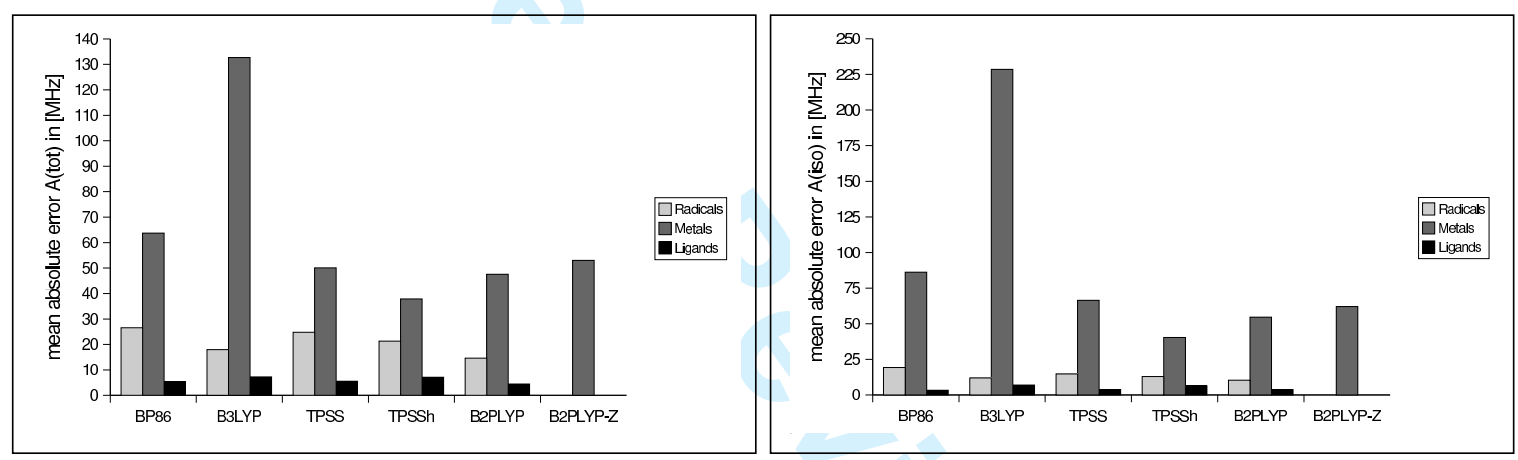

Figure 3: Graphical representation of the mean absolute error for the calculation of hyperfine coupling constants depending on the functional and the system. 


\section{List of Tables}

1 Isotopes, nuclear spins I and scaled nuclear g-values $\left(\mathrm{P}=\mathrm{g}_{e} \mathrm{~g}_{N} \beta_{e} \beta_{N}\right.$ in $\left.\mathrm{MHz} / \mathrm{au}^{3}\right)$ used in the calculations. . . . . . . . . . . . . . . . . . . . . . . 31

2 Hyperfine coupling constants in $\mathrm{MHz}$ for a variety of small $\mathrm{S}=1 / 2$ systems. . . . . . . . 32

3 Hyperfine coupling constants in $\mathrm{MHz}$ for a variety of $\mathrm{S} \geq 1 / 2$ systems. . . . . . . . . . 34

4 Hyperfine coupling constants in $\mathrm{MHz}$ for a variety of small $\mathrm{S}=1 / 2$ radicals. . . . . . . . 35

$5 \quad$ Hyperfine coupling constants in $\mathrm{MHz}$ for a variety of small $\mathrm{S}=1 / 2$ radicals. . . . . . . . 36

6 Hyperfine coupling constants in $\mathrm{MHz}$ for a variety of small $\mathrm{S} \geq 1 / 2$ radicals. . . . . . . . 38

$7 \quad$ Metal nucleus hyperfine coupling constants in MHz. . . . . . . . . . . . . . . . . . . 40

$8 \quad$ Metal nucleus hyperfine coupling constants in MHz. . . . . . . . . . . . . . . . . . . 41

$9 \quad$ Hyperfine coupling constants in $\mathrm{MHz}$ for a series of ligand atoms. . . . . . . . . . . . 42

10 Hyperfine coupling constants in $\mathrm{MHz}$ for selected radicals. The structures were optimized with the same functional with which the HFCs are calculated. . . . . . . . . . . . . . 43 
Table 1: Isotopes, nuclear spins I and scaled nuclear g-values $\left(\mathrm{P}=\mathrm{g}_{e} \mathrm{~g}_{N} \beta_{e} \beta_{N}\right.$ in $\left.\mathrm{MHz} / \mathrm{au}^{3}\right)$ used in the calculations.

\begin{tabular}{lrr}
\hline \hline Metal nucleus & $\mathrm{I}$ & $\mathrm{P}$ \\
\hline${ }^{45} \mathrm{Sc}$ & $7 / 2$ & 129.8189 \\
${ }^{47} \mathrm{Ti}$ & $5 / 2$ & -30.1264 \\
${ }^{51} \mathrm{~V}$ & $7 / 2$ & 140.2594 \\
${ }^{53} \mathrm{Cr}$ & $3 / 2$ & -30.0605 \\
${ }^{55} \mathrm{Mn}$ & $5 / 2$ & 132.0006 \\
${ }^{57} \mathrm{Fe}$ & $1 / 2$ & 17.2511 \\
${ }^{61} \mathrm{Ni}$ & $3 / 2$ & -47.7615 \\
${ }^{63} \mathrm{Cu}$ & $3 / 2$ & 141.7533 \\
\hline \hline
\end{tabular}


Table 2: Hyperfine coupling constants in $\mathrm{MHz}$ for a variety of small $\mathrm{S}=1 / 2$ systems.

\begin{tabular}{|c|c|c|c|c|c|c|c|c|c|}
\hline & & & $\mathrm{A}_{11}^{(\mathrm{A})}$ & $\mathrm{A}_{22}^{(\mathrm{A})}$ & $\mathrm{A}_{33}^{(\mathrm{A})}$ & $\mathrm{A}^{(\mathrm{A} ; \mathrm{c})}$ & $\mathrm{A}_{11}^{(\mathrm{A} ; \mathrm{d})}$ & $\mathrm{A}_{22}^{(\mathrm{A} ; \mathrm{d})}$ & $\mathrm{A}_{33}^{(\mathrm{A} ; \mathrm{d})}$ \\
\hline \multirow[t]{12}{*}{$\mathrm{CN}$} & $\mathrm{BP}$ & ${ }^{13} \mathrm{C}$ & 437.8 & 437.8 & 615.8 & 497.1 & -59.4 & -59.4 & 118.7 \\
\hline & B3LYP & ${ }^{13} \mathrm{C}$ & 512.9 & 512.9 & 692.7 & 572.8 & -59.9 & -59.9 & 119.9 \\
\hline & TPSS & ${ }^{13} \mathrm{C}$ & 459.4 & 459.4 & 637.1 & 518.6 & -59.3 & -59.3 & 118.5 \\
\hline & TPSSh & ${ }^{13} \mathrm{C}$ & 497.1 & 497.1 & 672.4 & 555.5 & -58.4 & -58.4 & 116.8 \\
\hline & B2PLYP & ${ }^{13} \mathrm{C}$ & 343.1 & 343.1 & 555.3 & 413.8 & -70.7 & -70.7 & 141.5 \\
\hline & Expt [76] & & 543 & 543 & 678 & 588 & -45 & -45 & 90 \\
\hline & BP & ${ }^{14} \mathrm{~N}$ & -35.5 & -35.5 & 29.3 & -13.9 & -21.6 & -21.6 & 43.2 \\
\hline & B3LYP & ${ }^{14} \mathrm{~N}$ & -40.5 & -40.5 & 24.4 & -18.9 & -21.7 & -21.7 & 43.3 \\
\hline & TPSS & ${ }^{14} \mathrm{~N}$ & -39.2 & -39.2 & 26.8 & -17.2 & -22.0 & -22.0 & 44.0 \\
\hline & TPSSh & ${ }^{14} \mathrm{~N}$ & -44.2 & -44.2 & 21.9 & -22.2 & -22.0 & -22.0 & 44.0 \\
\hline & B2PLYP & ${ }^{14} \mathrm{~N}$ & -44.1 & -44.1 & 14.0 & -24.7 & -19.3 & -19.3 & 38.7 \\
\hline & Expt [76] & & -28 & -28 & 27 & -13 & -15 & -15 & 30 \\
\hline \multirow[t]{12}{*}{$\mathrm{CO}^{+}$} & $\mathrm{BP}$ & ${ }^{13} \mathrm{C}$ & 1428.2 & 1428.2 & 1582.1 & 1479.5 & -51.3 & -51.3 & 102.6 \\
\hline & B3LYP & ${ }^{13} \mathrm{C}$ & 1540.7 & 1540.7 & 1694.5 & 1591.9 & -51.3 & -51.3 & 102.6 \\
\hline & TPSS & ${ }^{13} \mathrm{C}$ & 1444.4 & 1444.4 & 1596.0 & 1494.9 & -50.6 & -50.6 & 101.1 \\
\hline & TPSSh & ${ }^{13} \mathrm{C}$ & 1481.0 & 1481.0 & 1628.5 & 1530.2 & -49.2 & -49.2 & 98.3 \\
\hline & B2PLYP & ${ }^{13} \mathrm{C}$ & 1497.1 & 1497.1 & 1662.3 & 1552.2 & -55.1 & -55.1 & 110.2 \\
\hline & Expt $[77]$ & & 1524 & 1524 & 1671 & 1573 & -49 & -49 & 98 \\
\hline & $\mathrm{BP}$ & ${ }^{17} \mathrm{O}$ & -50.6 & 70.7 & 70.7 & 30.3 & -80.9 & 40.4 & 40.4 \\
\hline & B3LYP & ${ }^{17} \mathrm{O}$ & -50.4 & 68.0 & 68.0 & 28.5 & -78.9 & 39.5 & 39.5 \\
\hline & TPSS & ${ }^{17} \mathrm{O}$ & -53.0 & 75.0 & 75.0 & 32.3 & -85.3 & 42.7 & 42.7 \\
\hline & TPSSh & ${ }^{17} \mathrm{O}$ & -53.8 & 75.3 & 75.3 & 32.2 & -86.0 & 43.0 & 43.0 \\
\hline & B2PLYP & ${ }^{17} \mathrm{O}$ & -45.9 & 56.3 & 56.3 & 22.2 & -68.1 & 34.1 & 34.1 \\
\hline & Expt [77] & & -47 & 52 & 52 & 19 & -66 & 33 & 33 \\
\hline \multirow[t]{11}{*}{$\mathrm{BO}$} & BP & ${ }^{11} \mathrm{~B}$ & 964.2 & 964.2 & 1044.4 & 990.9 & -26.7 & -26.7 & 53.5 \\
\hline & B3LYP & ${ }^{11} \mathrm{~B}$ & 1048.1 & 1048.1 & 1131.2 & 1075.8 & -27.7 & -27.7 & 55.4 \\
\hline & TPSS & ${ }^{11} \mathrm{~B}$ & 964.7 & 964.7 & 1046.1 & 991.8 & -27.2 & -27.2 & 54.3 \\
\hline & TPSSh & ${ }^{11} \mathrm{~B}$ & 980.8 & 980.8 & 1061.0 & 1007.6 & -26.7 & -26.7 & 53.5 \\
\hline & B2PLYP & ${ }^{11} \mathrm{~B}$ & 1033.4 & 1033.4 & 1116.7 & 1061.2 & -27.8 & -27.8 & 55.5 \\
\hline & Expt $[78]$ & & 998 & 998 & 1079 & 1025 & -27 & -27 & 54 \\
\hline & $\mathrm{BP}$ & ${ }^{17} \mathrm{O}$ & -54.4 & 15.6 & 15.6 & -7.7 & -46.7 & 23.3 & 23.3 \\
\hline & B3LYP & ${ }^{17} \mathrm{O}$ & -54.2 & 10.4 & 10.4 & -11.1 & -43.1 & 21.5 & 21.5 \\
\hline & TPSS & ${ }^{17} \mathrm{O}$ & -55.4 & 19.6 & 19.6 & -5.4 & -50.0 & 25.0 & 25.0 \\
\hline & TPSSh & ${ }^{17} \mathrm{O}$ & -56.3 & 18.2 & 18.2 & -6.7 & -49.6 & 24.8 & 24.8 \\
\hline & B2PLYP & ${ }^{17} \mathrm{O}$ & -55.7 & 5.5 & 5.5 & -14.9 & -40.8 & 20.4 & 20.4 \\
\hline \multirow[t]{11}{*}{$\mathrm{AlO}$} & $\mathrm{BP}$ & ${ }^{27} \mathrm{Al}$ & 598.3 & 598.3 & 769.1 & 655.2 & -56.9 & -56.9 & 113.9 \\
\hline & B3LYP & ${ }^{27} \mathrm{Al}$ & 451.5 & 451.5 & 631.7 & 511.6 & -60.1 & -60.1 & 120.2 \\
\hline & TPSS & ${ }^{27} \mathrm{Al}$ & 593.8 & 593.8 & 762.9 & 650.2 & -56.4 & -56.4 & 112.7 \\
\hline & TPSSh & ${ }^{27} \mathrm{Al}$ & 534.4 & 534.4 & 706.0 & 591.6 & -57.2 & -57.2 & 114.4 \\
\hline & B2PLYP & ${ }^{27} \mathrm{Al}$ & 922.5 & 922.5 & 1095.1 & 980.0 & -57.5 & -57.5 & 115.0 \\
\hline & Expt [79] & & 713 & 713 & 872 & 766 & -53 & -53 & 106 \\
\hline & $\mathrm{BP}$ & ${ }^{17} \mathrm{O}$ & -104.4 & 73.8 & 73.8 & 14.4 & -118.9 & 59.4 & 59.4 \\
\hline & B3LYP & ${ }^{17} \mathrm{O}$ & -124.1 & 74.5 & 74.5 & 8.3 & -132.4 & 66.2 & 66.2 \\
\hline & TPSS & ${ }^{17} \mathrm{O}$ & -108.5 & 70.2 & 70.2 & 10.7 & -119.2 & 59.6 & 59.6 \\
\hline & TPSSh & ${ }^{17} \mathrm{O}$ & -109.1 & 74.7 & 74.7 & 13.4 & -122.5 & 61.3 & 61.3 \\
\hline & B2PLYP & ${ }^{17} \mathrm{O}$ & -66.7 & 63.1 & 63.1 & 19.9 & -86.6 & 43.3 & 43.3 \\
\hline \multirow[t]{12}{*}{$\mathrm{MgF}$} & $\mathrm{BP}$ & ${ }^{25} \mathrm{Mg}$ & -313.2 & -300.8 & -300.8 & -304.9 & -8.3 & 4.1 & 4.1 \\
\hline & B3LYP & ${ }^{25} \mathrm{Mg}$ & -330.7 & -318.4 & -318.4 & -322.5 & -8.2 & 4.1 & 4.1 \\
\hline & TPSS & ${ }^{25} \mathrm{Mg}$ & -291.9 & -278.9 & -278.9 & -283.2 & -8.6 & 4.3 & 4.3 \\
\hline & TPSSh & ${ }^{25} \mathrm{Mg}$ & -294.6 & -281.8 & -281.8 & -286.1 & -8.5 & 4.3 & 4.3 \\
\hline & B2PLYP & ${ }^{25} \mathrm{Mg}$ & -324.7 & -312.7 & -312.7 & -316.7 & -8.0 & 4.0 & 4.0 \\
\hline & Expt $[80]$ & & -349 & -331 & -331 & -337 & -12 & 6 & 6 \\
\hline & $\mathrm{BP}$ & ${ }^{19} \mathrm{~F}$ & 81.6 & 81.6 & 373.9 & 179.0 & -97.4 & -97.4 & 194.9 \\
\hline & B3LYP & ${ }^{19} \mathrm{~F}$ & 116.7 & 116.7 & 387.5 & 207.0 & -90.3 & -90.3 & 180.6 \\
\hline & TPSS & ${ }^{19} \mathrm{~F}$ & 68.1 & 68.1 & 378.7 & 171.7 & -103.5 & -103.5 & 207.0 \\
\hline & TPSSh & ${ }^{19} \mathrm{~F}$ & 81.0 & 81.0 & 367.6 & 176.5 & -95.5 & -95.5 & 191.0 \\
\hline & B2PLYP & ${ }^{19} \mathrm{~F}$ & 128.1 & 128.1 & 364.8 & 207.0 & -78.9 & -78.9 & 157.8 \\
\hline & Expt [81] & & 143 & 143 & 332 & 206 & -63 & -63 & 126 \\
\hline \multirow[t]{11}{*}{ BS } & BP & ${ }^{11} \mathrm{~B}$ & 753.5 & 753.5 & 842.9 & 783.3 & -29.8 & -29.8 & 59.6 \\
\hline & B3LYP & ${ }^{11} \mathrm{~B}$ & 794.6 & 794.6 & 889.8 & 826.3 & -31.7 & -31.7 & 63.5 \\
\hline & TPSS & ${ }^{11} \mathrm{~B}$ & 757.0 & 757.0 & 848.1 & 787.3 & -30.4 & -30.4 & 60.7 \\
\hline & TPSSh & ${ }^{11} \mathrm{~B}$ & 762.9 & 762.9 & 853.4 & 793.1 & -30.2 & -30.2 & 60.4 \\
\hline & B2PLYP & ${ }^{11} \mathrm{~B}$ & 790.7 & 790.7 & 885.1 & 822.2 & -31.5 & -31.5 & 63.0 \\
\hline & Expt [82] & & & & & 796 & & & \\
\hline & $\mathrm{BP}$ & ${ }^{33} \mathrm{~S}$ & -20.1 & -20.1 & 49.4 & 3.1 & -23.1 & -23.1 & 46.3 \\
\hline & B3LYP & ${ }^{33} \mathrm{~S}$ & -20.5 & -20.5 & 46.8 & 1.9 & -22.5 & -22.5 & 44.9 \\
\hline & TPSS & ${ }^{33} \mathrm{~S}$ & -21.5 & -21.5 & 49.3 & 2.1 & -23.6 & -23.6 & 47.2 \\
\hline & TPSSh & ${ }^{33} \mathrm{~S}$ & -22.1 & -22.1 & 49.2 & 1.7 & -23.7 & -23.7 & 47.5 \\
\hline & B2PLYP & ${ }^{33} \mathrm{~S}$ & -15.9 & -15.9 & 47.6 & 5.3 & -21.2 & -21.2 & 42.4 \\
\hline
\end{tabular}


Table 3: Hyperfine coupling constants in $\mathrm{MHz}$ for a variety of $\mathrm{S} \geq 1 / 2$ systems.

\begin{tabular}{|c|c|c|c|c|c|c|c|c|c|}
\hline & & & $\mathrm{A}_{11}^{(\mathrm{A})}$ & $\mathrm{A}_{22}^{(\mathrm{A})}$ & $\mathrm{A}_{33}^{(\mathrm{A})}$ & $\mathrm{A}^{(\mathrm{A} ; \mathrm{c})}$ & $\mathrm{A}_{11}^{(\mathrm{A} ; \mathrm{d})}$ & $\mathrm{A}_{22}^{(\mathrm{A} ; \mathrm{d})}$ & $\mathrm{A}_{33}^{(\mathrm{A} ; \mathrm{d})}$ \\
\hline $\mathrm{OH}$ & $\mathrm{BP}$ & ${ }^{17} \mathrm{O}$ & -308.6 & 124.4 & 126.7 & -19.2 & -289.4 & 143.6 & 145.9 \\
\hline \multirow{9}{*}{$\mathrm{S}=1 / 2$} & B3LYP & ${ }^{17} \mathrm{O}$ & -332.8 & 99.4 & 100.9 & -44.2 & -288.6 & 143.5 & 145.1 \\
\hline & TPSS & ${ }^{17} \mathrm{O}$ & -335.2 & 98.8 & 102.0 & -44.8 & -290.4 & 143.6 & 146.8 \\
\hline & TPSSh & ${ }^{17} \mathrm{O}$ & -337.5 & 95.0 & 98.1 & -48.1 & -289.4 & 143.2 & 146.3 \\
\hline & $\begin{array}{l}\text { B2PLYP } \\
\text { Expt [31] }\end{array}$ & ${ }^{17} \mathrm{O}$ & -336.9 & 90.2 & 91.5 & $\begin{array}{l}-51.7 \\
-51\end{array}$ & -285.2 & 142.0 & 143.2 \\
\hline & BP & ${ }^{1} \mathrm{H}$ & -133.2 & -79.3 & 24.1 & -62.8 & -70.4 & -16.5 & 86.9 \\
\hline & B3LYP & ${ }^{1} \mathrm{H}$ & -137.2 & -83.7 & 22.9 & -66.0 & -71.2 & -17.7 & 88.9 \\
\hline & TPSS & ${ }^{1} \mathrm{H}$ & -132.4 & -78.5 & 25.9 & -61.7 & -70.7 & -16.8 & 87.5 \\
\hline & TPSSh & ${ }^{1} \mathrm{H}$ & -136.0 & -81.9 & 23.4 & -64.8 & -71.1 & -17.1 & 88.2 \\
\hline & $\begin{array}{l}\text { B2PLYP } \\
\text { Expt [31] }\end{array}$ & ${ }^{1} \mathrm{H}$ & -141.9 & -87.8 & 19.3 & $\begin{aligned} & -70.2 \\
\sim & -69\end{aligned}$ & -71.8 & -17.7 & 89.4 \\
\hline $\mathrm{NO}$ & $\mathrm{BP}$ & ${ }^{14} \mathrm{~N}$ & -31.4 & -30.2 & 80.5 & 6.3 & -37.7 & -36.5 & 74.2 \\
\hline \multirow[t]{9}{*}{$\mathrm{S}=1 / 2$} & B3LYP & ${ }^{14} \mathrm{~N}$ & -20.9 & -19.6 & 95.3 & 18.3 & -39.2 & -37.9 & 77.0 \\
\hline & TPSS & ${ }^{14} \mathrm{~N}$ & -20.6 & -18.3 & 93.8 & 18.3 & -38.9 & -36.6 & 75.5 \\
\hline & TPSSh & ${ }^{14} \mathrm{~N}$ & -18.8 & -16.2 & 97.1 & 20.7 & -39.5 & -36.9 & 76.4 \\
\hline & $\begin{array}{l}\text { B2PLYP } \\
\text { Expt [83] }\end{array}$ & ${ }^{14} \mathrm{~N}$ & -18.8 & -15.0 & 50.6 & $\begin{array}{c}5.6 \\
22\end{array}$ & -24.4 & -20.6 & 45.0 \\
\hline & $\begin{array}{r}\text { Expt [83] } \\
\text { BP }\end{array}$ & ${ }^{17} \mathrm{O}$ & -143.4 & 53.3 & 62.7 & $\begin{array}{l}22 \\
-9.1\end{array}$ & -134.2 & 62.4 & 71.8 \\
\hline & B3LYP & ${ }^{17} \mathrm{O}$ & -163.1 & 37.7 & 47.3 & -26.0 & -137.1 & 63.7 & 73.3 \\
\hline & TPSS & ${ }^{17} \mathrm{O}$ & -165.0 & 31.4 & 42.4 & -30.4 & -134.6 & 61.8 & 72.8 \\
\hline & TPSSh & ${ }^{17} \mathrm{O}$ & -169.3 & 27.5 & 39.1 & -34.2 & -135.0 & 61.7 & 73.3 \\
\hline & B2PLYP & ${ }^{17} \mathrm{O}$ & -109.1 & 15.6 & 27.5 & -22.0 & -87.1 & 37.6 & 49.5 \\
\hline $\mathrm{NH}$ & $\mathrm{BP}$ & ${ }^{14} \mathrm{~N}$ & -36.2 & 32.6 & 32.6 & 9.7 & -45.9 & 22.9 & 22.9 \\
\hline \multirow[t]{11}{*}{$\mathrm{S}=1$} & B3LYP & ${ }^{14} \mathrm{~N}$ & -26.3 & 42.4 & 42.4 & 19.5 & -45.9 & 22.9 & 22.9 \\
\hline & TPSS & ${ }^{14} \mathrm{~N}$ & -24.1 & 46.2 & 46.2 & 22.8 & -46.9 & 23.4 & 23.4 \\
\hline & TPSSh & ${ }^{14} \mathrm{~N}$ & -23.0 & 46.9 & 46.9 & 23.6 & -46.6 & 23.3 & 23.3 \\
\hline & B2PLYP & ${ }^{14} \mathrm{~N}$ & -23.7 & 44.0 & 44.0 & 21.4 & -45.1 & 22.6 & 22.6 \\
\hline & Expt [83] & & -26 & 43 & 43 & 20 & -46 & 23 & 23 \\
\hline & $\mathrm{BP}$ & ${ }^{1} \mathrm{H}$ & -85.0 & -85.0 & 4.8 & -55.1 & -29.9 & -29.9 & 59.9 \\
\hline & B3LYP & ${ }^{1} \mathrm{H}$ & -86.8 & -86.8 & 5.5 & -56.0 & -30.8 & -30.8 & 61.5 \\
\hline & TPSS & ${ }^{1} \mathrm{H}$ & -67.4 & -67.4 & 21.4 & -37.8 & -29.6 & -29.6 & 59.2 \\
\hline & TPSSh & ${ }^{1} \mathrm{H}$ & -71.9 & -71.9 & 17.7 & -42.1 & -29.9 & -29.9 & 59.8 \\
\hline & B2PLYP & ${ }^{1} \mathrm{H}$ & -91.8 & -91.8 & 1.1 & -60.9 & -31.0 & -31.0 & 62.0 \\
\hline & Expt [83] & & -100 & -100 & -10 & -70 & -30 & -30 & 60 \\
\hline $\mathrm{OH}^{+}$ & $\mathrm{BP}$ & ${ }^{17} \mathrm{O}$ & -93.7 & -93.7 & 150.8 & -12.2 & -81.5 & -81.5 & 163.0 \\
\hline \multirow[t]{9}{*}{$\mathrm{S}=1$} & B3LYP & ${ }^{17} \mathrm{O}$ & -118.5 & -118.5 & 125.1 & -37.3 & -81.2 & -81.2 & 162.4 \\
\hline & TPSS & ${ }^{17} \mathrm{O}$ & -130.9 & -130.9 & 114.8 & -49.0 & -81.9 & -81.9 & 163.8 \\
\hline & TPSSh & ${ }^{17} \mathrm{O}$ & -133.3 & -133.3 & 111.1 & -51.8 & -81.5 & -81.5 & 163.0 \\
\hline & B2PLYP & ${ }^{17} \mathrm{O}$ & -127.1 & -127.1 & 113.1 & -47.0 & -80.1 & -80.1 & 160.2 \\
\hline & $\mathrm{BP}$ & ${ }^{1} \mathrm{H}$ & -105.7 & -105.7 & 21.0 & -63.5 & -42.3 & -42.3 & 84.5 \\
\hline & B3LYP & ${ }^{1} \mathrm{H}$ & -110.5 & -110.5 & 18.3 & -67.6 & -42.9 & -42.9 & 85.9 \\
\hline & TPSS & ${ }^{1} \mathrm{H}$ & -98.5 & -98.5 & 27.2 & -56.6 & -41.9 & -41.9 & 83.8 \\
\hline & TPSSh & ${ }^{1} \mathrm{H}$ & -102.5 & -102.5 & 23.9 & -60.4 & -42.2 & -42.2 & 84.3 \\
\hline & B2PLYP & ${ }^{1} \mathrm{H}$ & -115.9 & -115.9 & 13.7 & -72.7 & -43.2 & -43.2 & 86.4 \\
\hline $\mathrm{O}_{2}$ & $\mathrm{BP}$ & ${ }^{17} \mathrm{O}$ & -61.6 & -61.6 & 74.9 & -16.1 & -45.5 & -45.5 & 91.0 \\
\hline \multirow[t]{5}{*}{$\mathrm{S}=1$} & B3LYP & ${ }^{17} \mathrm{O}$ & -86.3 & -86.3 & 55.0 & -39.2 & -47.1 & -47.1 & 94.2 \\
\hline & TPSS & ${ }^{17} \mathrm{O}$ & -85.9 & -85.9 & 51.7 & -40.0 & -45.9 & -45.9 & 91.7 \\
\hline & TPSSh & ${ }^{17} \mathrm{O}$ & -92.2 & -92.2 & 47.1 & -45.8 & -46.4 & -46.4 & 92.9 \\
\hline & B2PLYP & ${ }^{17} \mathrm{O}$ & -93.1 & -93.1 & 45.3 & -47.0 & -46.1 & -46.1 & 92.2 \\
\hline & Expt [84] & & -102 & -102 & 39 & -55 & -47 & -47 & 94 \\
\hline $\mathrm{SH}^{+}$ & $\mathrm{BP}$ & ${ }^{33} \mathrm{~S}$ & -88.6 & 60.9 & 60.9 & 11.1 & -99.7 & 49.8 & 49.8 \\
\hline \multirow[t]{9}{*}{$\mathrm{S}=1$} & B3LYP & ${ }^{33} \mathrm{~S}$ & -76.2 & 74.9 & 74.9 & 24.6 & -100.8 & 50.4 & 50.4 \\
\hline & TPSS & ${ }^{33} \mathrm{~S}$ & -53.8 & 97.1 & 97.1 & 46.8 & -100.6 & 50.3 & 50.3 \\
\hline & TPSSh & ${ }^{33} \mathrm{~S}$ & -52.1 & 98.6 & 98.6 & 48.3 & -100.5 & 50.2 & 50.2 \\
\hline & B2PLYP & ${ }^{33} \mathrm{~S}$ & -63.8 & 84.1 & 84.1 & 34.8 & -98.6 & 49.3 & 49.3 \\
\hline & $\mathrm{BP}$ & ${ }^{1} \mathrm{H}$ & -61.0 & -61.0 & -24.9 & -49.0 & -12.0 & -12.0 & 24.0 \\
\hline & B3LYP & ${ }^{1} \mathrm{H}$ & -58.7 & -58.7 & -22.2 & -46.5 & -12.1 & -12.1 & 24.3 \\
\hline & TPSS & ${ }^{1} \mathrm{H}$ & -50.7 & -50.7 & -14.3 & -38.6 & -12.2 & -12.2 & 24.3 \\
\hline & TPSSh & ${ }^{1} \mathrm{H}$ & -52.5 & -52.5 & -15.9 & -40.3 & -12.2 & -12.2 & 24.4 \\
\hline & B2PLYP & ${ }^{1} \mathrm{H}$ & -67.3 & -67.3 & -30.8 & -55.1 & -12.2 & -12.2 & 24.4 \\
\hline $\mathrm{S}_{2}$ & $\mathrm{BP}$ & ${ }^{33} \mathrm{~S}$ & -49.8 & 25.3 & 25.3 & 0.3 & -50.1 & 25.0 & 25.0 \\
\hline \multirow[t]{4}{*}{$\mathrm{S}=1$} & B3LYP & ${ }^{33} \mathrm{~S}$ & -41.6 & 36.4 & 36.4 & 10.4 & -52.1 & 26.0 & 26.0 \\
\hline & TPSS & ${ }^{33} \mathrm{~S}$ & -37.3 & 37.9 & 37.9 & 12.8 & -50.1 & 25.0 & 25.0 \\
\hline & TPSSh & ${ }^{33} \mathrm{~S}$ & -35.6 & 40.4 & 40.4 & 15.0 & -50.7 & 25.3 & 25.3 \\
\hline & B2PLYP & ${ }^{33} \mathrm{~S}$ & -36.2 & 40.9 & 40.9 & 15.2 & -51.4 & 25.7 & 25.7 \\
\hline $\mathrm{SO}$ & $\mathrm{BP}$ & ${ }^{33} \mathrm{~S}$ & -65.7 & 25.4 & 25.4 & -5.0 & -60.7 & 30.4 & 30.4 \\
\hline $\mathrm{S}=1$ & B3LYP & ${ }^{33} \mathrm{~S}$ & -56.0 & 39.1 & 39.1 & 7.4 & -63.4 & 31.7 & 31.7 \\
\hline & TPSS & ${ }^{33} \mathrm{~S}$ & -51.3 & 39.8 & 39.8 & 9.4 & -60.8 & 30.4 & 30.4 \\
\hline & TPSSh & ${ }^{33} \mathrm{~S}$ & -50.1 & 42.4 & 42.4 & 11.6 & -61.7 & 30.8 & 30.8 \\
\hline & B2PLYP & ${ }^{33} \mathrm{~S}$ & -50.3 & 43.8 & 43.8 & 12.5 & -62.8 & 31.4 & 31.4 \\
\hline & $\mathrm{BP}$ & ${ }^{17} \mathrm{O}$ & -43.8 & -43.8 & 51.6 & -12.0 & -31.8 & -31.8 & 63.5 \\
\hline & B3LYP & ${ }^{17} \mathrm{O}$ & -61.2 & -61.2 & 37.2 & -28.4 & -32.8 & -32.8 & 65.6 \\
\hline & TPSS & ${ }^{17} \mathrm{O}$ & -59.2 & -59.2 & 37.2 & -27.1 & -32.1 & -32.1 & 64.3 \\
\hline & TPSSh & ${ }^{17} \mathrm{O}$ & -63.9 & -63.9 & 33.5 & -31.4 & -32.4 & -32.4 & 64.9 \\
\hline & B2PLYP & ${ }^{17} \mathrm{O}$ & -63.8 & -63.8 & 30.7 & -32.3 & -31.5 & -31.5 & 63.0 \\
\hline
\end{tabular}


Table 4: Hyperfine coupling constants in $\mathrm{MHz}$ for a variety of small $\mathrm{S}=1 / 2$ radicals. 
Table 5: Hyperfine coupling constants in $\mathrm{MHz}$ for a variety of small $\mathrm{S}=1 / 2$ radicals.

\begin{tabular}{|c|c|c|c|c|c|c|c|c|c|}
\hline & & & $\mathrm{A}_{11}^{(\mathrm{A})}$ & $\mathrm{A}_{22}^{(\mathrm{A})}$ & $\overline{A_{33}^{(A)}}$ & $\mathrm{A}^{(\mathrm{A} ; \mathrm{c})}$ & $\mathrm{A}_{11}^{(\mathrm{A} ; \mathrm{d})}$ & $\mathrm{A}_{22}^{(\mathrm{A} ; \mathrm{d})}$ & $\overline{A_{33}^{(A ; d)}}$ \\
\hline \multirow[t]{17}{*}{$\overline{\mathrm{H}_{2} \mathrm{CO}^{+}}$} & $\mathrm{BP}$ & ${ }^{13} \mathrm{C}$ & -97.7 & -69.4 & -56.3 & -74.5 & -23.3 & 5.1 & 18.2 \\
\hline & B3LYP & ${ }^{13} \mathrm{C}$ & -107.3 & -76.6 & -71.0 & -85.0 & -22.4 & 8.4 & 14.0 \\
\hline & TPSS & ${ }^{13} \mathrm{C}$ & -121.9 & -93.6 & -86.8 & -100.8 & -21.1 & 7.2 & 14.0 \\
\hline & TPSSh & ${ }^{13} \mathrm{C}$ & -125.3 & -95.3 & -92.1 & -104.2 & -21.1 & 8.9 & 12.1 \\
\hline & B2PLYP & ${ }^{13} \mathrm{C}$ & -117.9 & -89.0 & -85.6 & -97.5 & -20.4 & 8.5 & 11.9 \\
\hline & Expt [30] & & -124 & -105 & -99 & -109 & -15 & 4 & 10 \\
\hline & $\mathrm{BP}$ & ${ }^{17} \mathrm{O}$ & -262.5 & 94.0 & 115.2 & -17.8 & -244.7 & 111.7 & 133.0 \\
\hline & B3LYP & ${ }^{17} \mathrm{O}$ & -303.3 & 70.0 & 96.4 & -45.7 & -257.7 & 115.6 & 142.0 \\
\hline & TPSS & ${ }^{17} \mathrm{O}$ & -297.1 & 69.8 & 93.4 & -44.6 & -252.5 & 114.5 & 138.1 \\
\hline & TPSSh & ${ }^{17} \mathrm{O}$ & -308.1 & 64.2 & 91.0 & -51.0 & -257.1 & 115.1 & 142.0 \\
\hline & B2PLYP & ${ }^{17} \mathrm{O}$ & -316.0 & 61.4 & 84.6 & -56.7 & -259.4 & 118.0 & 141.3 \\
\hline & $\mathrm{BP}$ & ${ }^{1} \mathrm{H}$ & 328.4 & 330.9 & 360.1 & 339.8 & -11.4 & -8.9 & 20.3 \\
\hline & B3LYP & ${ }^{1} \mathrm{H}$ & 313.3 & 316.2 & 342.1 & 323.9 & -10.5 & -7.7 & 18.2 \\
\hline & TPSS & ${ }^{1} \mathrm{H}$ & 336.4 & 338.4 & 363.5 & 346.1 & -9.7 & -7.7 & 17.4 \\
\hline & TPSSh & ${ }^{1} \mathrm{H}$ & 324.5 & 326.7 & 350.0 & 333.7 & -9.2 & -7.1 & 16.3 \\
\hline & B2PLYP & ${ }^{1} \mathrm{H}$ & 313.8 & 316.3 & 341.5 & 323.9 & -10.1 & -7.5 & 17.6 \\
\hline & Expt [30] & & 363 & 376 & 377 & 372 & -9 & 4 & 5 \\
\hline \multirow{10}{*}{$\mathrm{CO}_{2}^{-}$} & $\mathrm{BP}$ & ${ }^{13} \mathrm{C}$ & 244.9 & 249.2 & 334.6 & 276.2 & -31.3 & -27.0 & 58.4 \\
\hline & B3LYP & ${ }^{13} \mathrm{C}$ & 290.8 & 296.5 & 399.8 & 329.1 & -38.2 & -32.5 & 70.8 \\
\hline & TPSS & ${ }^{13} \mathrm{C}$ & 270.6 & 277.4 & 372.3 & 306.8 & -36.2 & -29.4 & 65.6 \\
\hline & TPSSh & ${ }^{13} \mathrm{C}$ & 280.8 & 288.7 & 389.8 & 319.8 & -38.9 & -31.1 & 70.0 \\
\hline & B2PLYP & ${ }^{13} \mathrm{C}$ & 297.2 & 303.3 & 403.5 & 334.7 & -37.5 & -31.3 & 68.8 \\
\hline & BP & ${ }^{17} \mathrm{O}$ & -139.8 & -54.1 & -48.5 & -80.8 & -59.0 & 26.7 & 32.3 \\
\hline & B3LYP & ${ }^{17} \mathrm{O}$ & -153.8 & -59.5 & -54.0 & -89.1 & -64.7 & 29.6 & 35.1 \\
\hline & TPSS & ${ }^{17} \mathrm{O}$ & -149.3 & -56.4 & -50.5 & -85.4 & -63.9 & 29.0 & 34.9 \\
\hline & TPSSh & ${ }^{17} \mathrm{O}$ & -151.0 & -55.8 & -49.5 & -85.5 & -65.6 & 29.6 & 36.0 \\
\hline & B2PLYP & ${ }^{17} \mathrm{O}$ & -157.3 & -67.1 & -60.5 & -95.0 & -62.3 & 27.9 & 34.4 \\
\hline \multirow{10}{*}{$\mathrm{H}_{2} \mathrm{O}^{+}$} & $\mathrm{BP}$ & ${ }^{17} \mathrm{O}$ & -344.3 & 118.8 & 123.1 & -34.1 & -310.2 & 153.0 & 157.2 \\
\hline & B3LYP & ${ }^{17} \mathrm{O}$ & -373.3 & 88.3 & 92.9 & -64.1 & -309.3 & 152.3 & 156.9 \\
\hline & TPSS & ${ }^{17} \mathrm{O}$ & -382.9 & 80.5 & 86.9 & -71.8 & -311.1 & 152.3 & 158.8 \\
\hline & TPSSh & ${ }^{17} \mathrm{O}$ & -387.1 & 74.1 & 80.8 & -77.4 & -309.7 & 151.5 & 158.2 \\
\hline & $\begin{array}{l}\text { B2PLYP } \\
\text { Expt [31] }\end{array}$ & ${ }^{17} \mathrm{O}$ & -382.4 & 73.1 & 78.1 & $\begin{array}{l}-77.1 \\
-83\end{array}$ & -305.4 & 150.2 & 155.1 \\
\hline & BP & ${ }^{1} \mathrm{H}$ & -122.4 & -93.3 & 1.9 & -71.2 & -51.2 & -22.0 & 73.2 \\
\hline & B3LYP & ${ }^{1} \mathrm{H}$ & -128.9 & -100.0 & -2.6 & -77.2 & -51.7 & -22.8 & 74.6 \\
\hline & TPSS & ${ }^{1} \mathrm{H}$ & -123.6 & -94.5 & 0.9 & -72.4 & -51.2 & -22.1 & 73.3 \\
\hline & TPSSh & ${ }^{1} \mathrm{H}$ & -127.5 & -98.4 & -2.2 & -76.0 & -51.5 & -22.4 & 73.8 \\
\hline & $\begin{array}{l}\text { B2PLYP } \\
\text { Expt [31] }\end{array}$ & ${ }^{1} \mathrm{H}$ & -131.6 & -102.4 & -4.8 & $\begin{array}{l}-79.6 \\
-73\end{array}$ & -52.0 & -22.8 & 74.8 \\
\hline \multirow[t]{15}{*}{$\mathrm{O}_{2} \mathrm{H}$} & $\mathrm{BP}$ & ${ }^{17} \mathrm{O}$ & -252.5 & 95.0 & 95.7 & -20.6 & -231.8 & 115.6 & 116.3 \\
\hline & B3LYP & ${ }^{17} \mathrm{O}$ & -293.4 & 72.4 & 74.4 & -48.8 & -244.5 & 121.3 & 123.2 \\
\hline & TPSS & ${ }^{17} \mathrm{O}$ & -281.1 & 72.9 & 76.4 & -43.9 & -237.1 & 116.8 & 120.3 \\
\hline & TPSSh & ${ }^{17} \mathrm{O}$ & -293.5 & 69.1 & 72.1 & -50.8 & -242.7 & 119.8 & 122.9 \\
\hline & B2PLYP & ${ }^{17} \mathrm{O}$ & -301.3 & 59.6 & 63.3 & -59.5 & -241.8 & 119.1 & 122.8 \\
\hline & BP & ${ }^{17} \mathrm{O}$ & -128.4 & 41.1 & 45.4 & -14.0 & -114.4 & 55.0 & 59.4 \\
\hline & B3LYP & ${ }^{17} \mathrm{O}$ & -138.8 & 23.8 & 29.2 & -28.6 & -110.2 & 52.4 & 57.8 \\
\hline & TPSS & ${ }^{17} \mathrm{O}$ & -144.3 & 22.8 & 27.5 & -31.3 & -113.0 & 54.1 & 58.9 \\
\hline & TPSSh & ${ }^{17} \mathrm{O}$ & -144.3 & 17.5 & 22.9 & -34.6 & -109.6 & 52.1 & 57.5 \\
\hline & B2PLYP & ${ }^{17} \mathrm{O}$ & -147.4 & 15.8 & 20.9 & -36.9 & -110.5 & 52.7 & 57.8 \\
\hline & BP & ${ }^{1} \mathrm{H}$ & -46.7 & -36.1 & 11.1 & -23.9 & -22.8 & -12.2 & 35.0 \\
\hline & B3LYP & ${ }^{1} \mathrm{H}$ & -47.6 & -38.9 & 8.8 & -25.9 & -21.7 & -13.0 & 34.6 \\
\hline & TPSS & ${ }^{1} \mathrm{H}$ & -41.2 & -31.2 & 14.4 & -19.4 & -21.9 & -11.8 & 33.7 \\
\hline & TPSSh & ${ }^{1} \mathrm{H}$ & -41.9 & -32.7 & 12.6 & -20.6 & -21.2 & -12.0 & 33.3 \\
\hline & $\begin{array}{l}\text { B2PLYP } \\
\text { Expt [83] }\end{array}$ & ${ }^{1} \mathrm{H}$ & -51.3 & -41.9 & 6.5 & -28.9 & $\begin{array}{l}-22.4 \\
-11\end{array}$ & $\begin{array}{c}-13.1 \\
-8\end{array}$ & $\begin{array}{l}35.4 \\
20\end{array}$ \\
\hline \multirow{10}{*}{$\mathrm{O}_{3}^{-}$} & $\mathrm{BP}$ & ${ }^{17} \mathrm{O}$ & -174.7 & 44.6 & 47.6 & -27.5 & -147.2 & 72.1 & 75.1 \\
\hline & B3LYP & ${ }^{17} \mathrm{O}$ & -211.7 & 26.2 & 29.4 & -52.0 & -159.6 & 78.2 & 81.4 \\
\hline & TPSS & ${ }^{17} \mathrm{O}$ & -200.6 & 22.7 & 27.8 & -50.0 & -150.6 & 72.8 & 77.8 \\
\hline & TPSSh & ${ }^{17} \mathrm{O}$ & -214.2 & 17.1 & 22.4 & -58.2 & -156.0 & 75.3 & 80.6 \\
\hline & B2PLYP & ${ }^{17} \mathrm{O}$ & -204.7 & 20.7 & 24.4 & -53.2 & -151.5 & 74.0 & 77.6 \\
\hline & $\mathrm{BP}$ & ${ }^{17} \mathrm{O}$ & -114.3 & 41.5 & 42.9 & -10.0 & -104.3 & 51.5 & 52.8 \\
\hline & B3LYP & ${ }^{17} \mathrm{O}$ & -134.7 & 26.8 & 30.8 & -25.7 & -109.0 & 52.5 & 56.5 \\
\hline & TPSS & ${ }^{17} \mathrm{O}$ & -128.5 & 29.9 & 32.0 & -22.2 & -106.4 & 52.1 & 54.2 \\
\hline & TPSSh & ${ }^{17} \mathrm{O}$ & -134.4 & 26.7 & 28.0 & -26.6 & -107.9 & 53.3 & 54.6 \\
\hline & B2PLYP & ${ }^{17} \mathrm{O}$ & -131.4 & 27.5 & 29.8 & -24.7 & -106.7 & 52.2 & 54.5 \\
\hline
\end{tabular}


Table 6: Hyperfine coupling constants in $\mathrm{MHz}$ for a variety of small $\mathrm{S} \geq 1 / 2$ radicals.

\begin{tabular}{|c|c|c|c|c|c|c|c|c|c|}
\hline & & & $\overline{A_{11}^{(A)}}$ & $\overline{A_{22}^{(A)}}$ & $\mathrm{A}_{33}^{(\mathrm{A})}$ & $\overline{A^{(A ; c)}}$ & $\overline{\mathrm{A}_{11}^{(\mathrm{A} ; \mathrm{d})}}$ & $\overline{\mathrm{A}_{22}^{(\mathrm{A} ; \mathrm{d})}}$ & $\overline{\mathrm{A}_{33}^{(\mathrm{A} ; \mathrm{d})}}$ \\
\hline $\mathrm{N}$ & $\mathrm{BP}$ & $14 \mathrm{~N}$ & -0.1 & -0.1 & -0.1 & -0.1 & 0.0 & 0.0 & $\overline{0.0}$ \\
\hline \multirow[t]{4}{*}{$\mathrm{S}=3 / 2$} & B3LYP & ${ }^{14} \mathrm{~N}$ & 9.8 & 9.8 & 9.8 & 9.8 & 0.0 & 0.0 & 0.0 \\
\hline & TPSS & ${ }^{14} \mathrm{~N}$ & 8.0 & 8.0 & 8.0 & 8.0 & 0.0 & 0.0 & 0.0 \\
\hline & TPSSh & ${ }^{14} \mathrm{~N}$ & 8.4 & 8.4 & 8.4 & 8.4 & 0.0 & 0.0 & 0.0 \\
\hline & $\begin{array}{l}\text { B2PLYP } \\
\text { Expt [31] }\end{array}$ & ${ }^{14} \mathrm{~N}$ & 11.4 & 11.4 & 11.4 & $\begin{array}{l}11.4 \\
10\end{array}$ & -0.0 & 0.0 & 0.0 \\
\hline \multirow[t]{12}{*}{$\mathrm{NH}_{2}$} & BP & ${ }^{14} \mathrm{~N}$ & -26.9 & -25.9 & 106.3 & 17.8 & -44.7 & -43.8 & 88.5 \\
\hline & B3LYP & ${ }^{14} \mathrm{~N}$ & -16.2 & -15.3 & 117.1 & 28.5 & -44.7 & -43.8 & 88.6 \\
\hline & TPSS & ${ }^{14} \mathrm{~N}$ & -14.7 & -13.1 & 120.0 & 30.7 & -45.4 & -43.9 & 89.3 \\
\hline & TPSSh & ${ }^{14} \mathrm{~N}$ & -12.9 & -11.3 & 121.3 & 32.4 & -45.3 & -43.6 & 88.9 \\
\hline & B2PLYP & ${ }^{14} \mathrm{~N}$ & -12.9 & -12.0 & 118.3 & 31.1 & -44.0 & -43.2 & 87.2 \\
\hline & Expt $[85,88]$ & & -17 & -15 & 116 & 28 & -45 & -43 & 88 \\
\hline & $\mathrm{BP}$ & ${ }^{1} \mathrm{H}$ & -114.7 & -65.5 & 0.5 & -59.9 & -54.8 & -5.6 & 60.4 \\
\hline & B3LYP & ${ }^{1} \mathrm{H}$ & -116.1 & -67.7 & 1.3 & -60.8 & -55.3 & -6.8 & 62.2 \\
\hline & TPSS & ${ }^{1} \mathrm{H}$ & -112.5 & -63.5 & 4.0 & -57.3 & -55.1 & -6.2 & 61.3 \\
\hline & TPSSh & ${ }^{1} \mathrm{H}$ & -116.2 & -67.0 & 1.1 & -60.7 & -55.5 & -6.3 & 61.8 \\
\hline & B2PLYP & ${ }^{1} \mathrm{H}$ & -120.2 & -71.3 & $\begin{array}{l}1.1 \\
-2.2\end{array}$ & -64.6 & -55.7 & -6.7 & 62.3 \\
\hline & Expt $[85,88]$ & & -123 & -72 & -1 & -67 & -56 & -5 & 66 \\
\hline \multirow{12}{*}{$\mathrm{NO}_{2}$} & $\mathrm{BP}$ & ${ }^{14} \mathrm{~N}$ & 122.1 & 123.6 & 178.6 & 141.5 & -19.3 & -17.8 & 37.2 \\
\hline & B3LYP & ${ }^{14} \mathrm{~N}$ & 123.4 & 126.2 & 186.6 & 145.4 & -22.0 & -19.2 & 41.2 \\
\hline & $\begin{array}{l}\text { TPSS } \\
\text { TPS }\end{array}$ & ${ }^{14} \mathrm{~N}$ & 122.4 & 124.8 & $\begin{array}{l}100.0 \\
181.3\end{array}$ & $\begin{array}{l}140.4 \\
142.8\end{array}$ & -20.5 & -18.0 & $\begin{array}{l}41.2 \\
38.5\end{array}$ \\
\hline & TPSSh & ${ }^{14} \mathrm{~N}$ & 121.5 & 124.6 & 183.4 & 143.1 & -21.7 & -18.5 & 40.2 \\
\hline & B2PLYP & ${ }^{14} \mathrm{~N}$ & 127.9 & 130.7 & 187.2 & 148.6 & -20.7 & -17.9 & 38.6 \\
\hline & Expt [46] & & 131 & 138 & 190 & 153 & -22 & -15 & 37 \\
\hline & $\mathrm{BP}$ & ${ }^{17} \mathrm{O}$ & -156.1 & 5.1 & 8.0 & -47.7 & -108.4 & 52.8 & 55.7 \\
\hline & B3LYP & ${ }^{17} \mathrm{O}$ & -165.4 & 2.0 & 4.0 & -53.1 & -112.3 & 55.1 & 57.2 \\
\hline & TPSS & ${ }^{17} \mathrm{O}$ & -167.1 & -1.3 & 1.2 & -55.7 & -111.4 & 54.5 & 56.9 \\
\hline & TPSSh & ${ }^{17} \mathrm{O}$ & -167.4 & 0.7 & 2.9 & -54.6 & -112.8 & 55.3 & 57.5 \\
\hline & B2PLYP & ${ }^{17} \mathrm{O}$ & -171.3 & -11.0 & -7.2 & -63.2 & -108.1 & 52.2 & 56.0 \\
\hline & Expt [46] & & $\sim-160$ & $\sim-7$ & $\sim 5$ & $-47--61$ & -106 & 47 & 59 \\
\hline \multirow{10}{*}{$\mathrm{NF}_{2}$} & $\mathrm{BP}$ & ${ }^{14} \mathrm{~N}$ & -21.3 & -18.7 & 119.8 & 26.6 & -47.9 & -45.3 & 93.2 \\
\hline & B3LYP & ${ }^{14} \mathrm{~N}$ & -6.9 & -3.9 & 142.4 & 43.9 & -50.8 & -47.7 & 98.5 \\
\hline & TPSS & ${ }^{14} \mathrm{~N}$ & 2.7 & -1.8 & 143.8 & 48.3 & -45.5 & -50.0 & 95.5 \\
\hline & TPSSh & ${ }^{14} \mathrm{~N}$ & 6.9 & 2.1 & 150.7 & 53.2 & -46.3 & -51.1 & 97.5 \\
\hline & B2PLYP & ${ }^{14} \mathrm{~N}$ & -1.5 & 1.7 & 147.5 & 49.2 & -50.7 & -47.5 & 98.2 \\
\hline & $\mathrm{BP}$ & ${ }^{19} \mathrm{~F}$ & -183.1 & -163.7 & 619.2 & 90.8 & -273.9 & -254.5 & 528.4 \\
\hline & B3LYP & ${ }^{19} \mathrm{~F}$ & -122.7 & -93.2 & 643.9 & 142.7 & -265.4 & -235.9 & 501.2 \\
\hline & TPSS & ${ }^{19} \mathrm{~F}$ & -89.7 & -68.9 & 690.0 & 177.1 & -266.8 & -246.1 & 512.8 \\
\hline & TPSSh & ${ }^{19} \mathrm{~F}$ & -64.5 & -45.1 & 688.3 & 192.9 & -257.4 & -238.0 & 495.4 \\
\hline & B2PLYP & ${ }^{19} \mathrm{~F}$ & -89.9 & -64.8 & 654.0 & 166.4 & -256.4 & -231.2 & 487.6 \\
\hline \multirow{12}{*}{$\mathrm{NF}_{3}^{+}$} & BP & ${ }^{14} \mathrm{~N}$ & 6.8 & $\begin{array}{r}-0.0 \\
6.8\end{array}$ & 140.0 & $\begin{array}{r}100.4 \\
51.2\end{array}$ & $\begin{array}{r}-200.4 \\
-44.4\end{array}$ & -44.4 & $\begin{array}{r}401.0 \\
88.8\end{array}$ \\
\hline & B3LYP & ${ }^{14} \mathrm{~N}$ & 27.1 & 27.1 & 170.8 & 75.0 & -47.9 & -47.9 & 95.8 \\
\hline & TPSS & ${ }^{14} \mathrm{~N}$ & 29.8 & 29.8 & 166.1 & 75.2 & -45.4 & -45.4 & 90.8 \\
\hline & TPSSh & ${ }^{14} \mathrm{~N}$ & 38.8 & 38.8 & 179.3 & 85.6 & -46.8 & -46.8 & 93.7 \\
\hline & B2PLYP & ${ }^{14} \mathrm{~N}$ & $\begin{array}{l}30.0 \\
31.4\end{array}$ & 31.4 & 176.4 & 79.7 & -48.4 & -48.4 & 96.7 \\
\hline & Expt [83] & & & & & 276 & & & \\
\hline & $\mathrm{BP}$ & ${ }^{19} \mathrm{~F}$ & -195.8 & -124.9 & 754.9 & 144.8 & -340.5 & -269.6 & 610.2 \\
\hline & B3LYP & ${ }^{19} \mathrm{~F}$ & -121.0 & -13.4 & 825.4 & 230.3 & -351.3 & -243.8 & 595.1 \\
\hline & TPSS & ${ }^{19} \mathrm{~F}$ & -105.1 & -32.3 & 841.6 & 234.8 & -339.8 & -267.0 & 606.8 \\
\hline & TPSSh & ${ }^{19} \mathrm{~F}$ & $\begin{array}{r}-100.1 \\
-78.1\end{array}$ & $\begin{array}{r}-52.0 \\
16.9\end{array}$ & 863.1 & $\begin{array}{l}207.0 \\
267.3\end{array}$ & -345.4 & -250.4 & 595.8 \\
\hline & B2PLYP & ${ }^{19} \mathrm{~F}$ & -81.5 & 21.1 & 836.8 & 258.8 & -340.3 & -237.7 & 578.0 \\
\hline & Expt [83] & & & & & 468 & & & \\
\hline \multirow[t]{11}{*}{$\mathrm{ClO}_{2}$} & $\mathrm{BP}$ & ${ }^{35} \mathrm{Cl}$ & -63.9 & -59.7 & 146.3 & 7.6 & -71.5 & -67.2 & 138.7 \\
\hline & B3LYP & ${ }^{35} \mathrm{Cl}$ & -52.1 & -47.0 & 172.1 & 24.3 & -76.4 & -71.4 & 147.8 \\
\hline & TPSS & ${ }^{35} \mathrm{Cl}$ & -43.7 & -37.7 & 165.0 & 27.9 & -71.6 & -65.6 & 137.1 \\
\hline & TPSSh & ${ }^{35} \mathrm{Cl}$ & -40.2 & -33.7 & 174.1 & 33.4 & -73.6 & -67.1 & 140.7 \\
\hline & B2PLYP & ${ }^{35} \mathrm{Cl}$ & -43.8 & -39.5 & 176.1 & 30.9 & -74.7 & -70.5 & 145.2 \\
\hline & Expt [83] & & & & & & -83 & -77 & 46 \\
\hline & $\mathrm{BP}$ & ${ }^{17} \mathrm{O}$ & -123.4 & 50.5 & 50.8 & -7.3 & -116.0 & 57.9 & 58.2 \\
\hline & B3LYP & ${ }^{17} \mathrm{O}$ & -143.7 & 38.2 & 38.7 & -22.3 & -121.4 & 60.4 & 61.0 \\
\hline & TPSS & ${ }^{17} \mathrm{O}$ & -139.7 & 37.2 & 39.9 & -20.9 & -118.8 & 58.1 & 60.7 \\
\hline & TPSSh & ${ }^{17} \mathrm{O}$ & -145.4 & 34.6 & 37.0 & -24.6 & -120.8 & 59.2 & 61.6 \\
\hline & B2PLYP & ${ }^{17} \mathrm{O}$ & -140.0 & 33.1 & 33.4 & -24.5 & -115.5 & 57.6 & 57.9 \\
\hline \multirow[t]{5}{*}{ mean error $^{a}$} & $\mathrm{BP}$ & & -11.7 & -10.7 & 5.7 & -2.4 & -4.3 & -3.6 & 13.1 \\
\hline & B3LYP & & 1.3 & 2.7 & 18.8 & 5.9 & -4.6 & -3.7 & 13.5 \\
\hline & TPSS & & -6.6 & -4.6 & 12.7 & 0.1 & -5.2 & -3.5 & 13.8 \\
\hline & TPSSh & & -4.5 & -2.1 & 13.6 & 0.9 & -5.0 & -3.0 & 13.1 \\
\hline & B2PLYP & & -1.9 & -1.9 & 12.0 & -1.4 & -3.1 & -3.4 & 11.6 \\
\hline \multirow{5}{*}{ mean absolute error ${ }^{a}$} & $\mathrm{BP}$ & & 26.1 & 28.8 & 24.8 & 19.3 & 6.5 & 6.5 & 14.8 \\
\hline & B3LYP & & 14.5 & 16.3 & 23.2 & 11.9 & 5.8 & 6.3 & 14.4 \\
\hline & TPSS & & 22.2 & 24.5 & 27.6 & 14.8 & 7.0 & 7.0 & 15.3 \\
\hline & TPSSh & & 18.8 & 21.0 & 24.2 & 12.9 & 6.4 & 6.6 & 14.4 \\
\hline & B2PLYP & & 12.4 & 12.7 & 18.7 & 10.3 & 4.8 & 5.4 & 13.0 \\
\hline
\end{tabular}

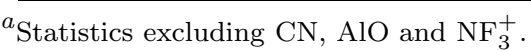


Table 7: Metal nucleus hyperfine coupling constants in MHz.

\begin{tabular}{|c|c|c|c|c|c|c|c|c|c|c|c|}
\hline & & $\mathrm{A}_{11}^{(\mathrm{M})}$ & $\mathrm{A}_{22}^{(\mathrm{M})}$ & $\mathrm{A}_{33}^{(\mathrm{M})}$ & $\mathrm{A}^{(\mathrm{M} ; \mathrm{c})}$ & $\mathrm{A}_{11}^{(\mathrm{M} ; \mathrm{d})}$ & $\mathrm{A}_{22}^{(\mathrm{M} ; \mathrm{d})}$ & $\mathrm{A}_{33}^{(\mathrm{M} ; \mathrm{d})}$ & $\mathrm{A}_{11}^{(\mathrm{M} ; \mathrm{SO})}$ & $\mathrm{A}_{22}^{(\mathrm{M} ; \mathrm{SO})}$ & $\mathrm{A}_{33}^{(\mathrm{M} ; \mathrm{SO})}$ \\
\hline $\mathrm{ScO}$ & $\mathrm{BP}$ & 2009.3 & 2009.3 & 2067.8 & 2028.8 & -19.3 & -19.3 & 38.5 & -0.9 & -0.9 & -0.1 \\
\hline \multirow[t]{6}{*}{$\mathrm{S}=1 / 2$} & B3LYP & 2058.7 & 2058.7 & 2120.2 & 2079.2 & -20.2 & -20.2 & 40.5 & -0.9 & -0.9 & -0.1 \\
\hline & TPSS & 1846.7 & 1846.7 & 1906.9 & 1866.8 & -19.8 & -19.8 & 39.6 & -0.8 & -0.8 & -0.1 \\
\hline & TPSSh & 1846.7 & 1846.7 & 1906.9 & 1866.8 & -19.8 & -19.8 & 39.6 & -0.8 & -0.8 & -0.1 \\
\hline & B2PLYP & 1906.8 & 1906.8 & 1970.9 & 1928.2 & -21.1 & -21.1 & 42.2 & -1.1 & -1.1 & -0.2 \\
\hline & B2PLYP-Z ${ }^{a}$ & 1987.8 & 1987.8 & 2058.7 & 2010.6 & -23.4 & -23.4 & 46.7 & -1.1 & -1.1 & -0.2 \\
\hline & Expt [89] & 1922 & 1922 & 1997 & 1947 & -25 & -25 & 50 & & & \\
\hline $\mathrm{MnH}$ & $\mathrm{BP}$ & 359.6 & 359.6 & 388.9 & 369.4 & -9.3 & -9.3 & 18.6 & -3.7 & -3.7 & -2.4 \\
\hline \multirow{6}{*}{$S=2$} & B3LYP & 318.2 & 318.2 & 350.1 & 328.9 & -10.1 & -10.1 & 20.3 & -3.5 & -3.5 & -2.0 \\
\hline & TPSS & 334.3 & 334.3 & 364.9 & 344.5 & -9.8 & -9.8 & 19.5 & -3.6 & -3.6 & -2.3 \\
\hline & TPSSh & 312.2 & 312.2 & 344.8 & 323.1 & -10.4 & -10.4 & 20.8 & -3.6 & -3.6 & -2.1 \\
\hline & B2PLYP & 258.6 & 258.6 & 292.8 & 270.0 & -11.0 & -11.0 & 21.9 & -3.1 & -3.1 & -1.7 \\
\hline & B2PLYP-Z a & 275.2 & 275.2 & 312.8 & 287.8 & -12.1 & -12.1 & 24.2 & -3.1 & -3.1 & -1.7 \\
\hline & Expt $[90]$ & 267 & 267 & 303 & 279 & -12 & -12 & 24 & & & \\
\hline $\mathrm{MnO}$ & $\mathrm{BP}$ & 517.6 & 594.3 & 594.3 & 568.7 & -52.8 & 26.4 & 26.4 & -3.2 & -5.7 & -5.7 \\
\hline \multirow[t]{6}{*}{$\mathrm{S}=3 / 2$} & B3LYP & 523.7 & 589.7 & 589.7 & 567.7 & -45.6 & 22.8 & 22.8 & -2.9 & -5.3 & -5.3 \\
\hline & TPSS & 505.3 & 577.8 & 577.8 & 553.6 & -49.8 & 24.9 & 24.9 & -3.1 & -5.2 & -5.2 \\
\hline & TPSSh & 497.7 & 564.3 & 564.3 & 542.1 & -45.9 & 22.9 & 22.9 & -2.9 & -5.1 & -5.1 \\
\hline & B2PLYP & 485.4 & 552.2 & 552.2 & 529.9 & -45.5 & 22.7 & 22.7 & -2.4 & -3.9 & -3.9 \\
\hline & B2PLYP-Z ${ }^{a}$ & 524.1 & 591.5 & 591.5 & 569.0 & -46.0 & 23.0 & 23.0 & -2.4 & -3.9 & -3.9 \\
\hline & Expt $[91]$ & 448 & 496 & 496 & 480 & -32 & 16 & 16 & & & \\
\hline $\mathrm{MnF}$ & $\mathrm{BP}$ & 498.7 & 498.7 & 517.2 & 504.9 & -6.0 & -6.0 & 12.0 & -3.0 & -3.0 & -2.5 \\
\hline $\mathrm{S}=2$ & B3LYP & 488.7 & 488.7 & 510.3 & 495.9 & -7.0 & -7.0 & 14.0 & -2.8 & -2.8 & -2.1 \\
\hline & TPSS & 475.5 & 475.5 & 495.9 & 482.3 & -6.6 & -6.6 & 13.2 & -3.0 & -3.0 & -2.4 \\
\hline & TPSSh & 457.4 & 457.4 & 480.1 & 465.0 & -7.3 & -7.3 & 14.7 & -2.9 & -2.9 & -2.2 \\
\hline & B2PLYP & 406.0 & 406.0 & 430.9 & 414.3 & -8.0 & -8.0 & 16.1 & -2.5 & -2.5 & -1.7 \\
\hline & B2PLYP-Z ${ }^{a}$ & 439.4 & 439.4 & 466.8 & 448.5 & -8.9 & -8.9 & 17.8 & -2.5 & -2.5 & -1.7 \\
\hline & Expt $[92]$ & 430 & 430 & 466 & 442 & -12 & -12 & 24 & & & \\
\hline $\mathrm{TiF}_{3}$ & $\mathrm{BP}$ & -252.8 & -223.7 & -222.8 & -233.1 & -18.1 & 8.7 & 9.4 & 2.7 & 2.5 & 0.2 \\
\hline $\mathrm{S}=1 / 2$ & B3LYP & -227.6 & -195.4 & -194.0 & -205.6 & -19.8 & 9.3 & 10.5 & 3.5 & 3.2 & 0.1 \\
\hline & TPSS & -232.8 & -206.5 & -205.5 & -215.0 & -16.6 & 7.8 & 8.8 & 2.2 & 2.1 & 0.2 \\
\hline & TPSSh & -219.0 & -192.2 & -190.9 & -200.7 & -16.9 & 7.9 & 9.0 & 2.4 & 2.3 & 0.2 \\
\hline & B2PLYP & -201.0 & -169.5 & -167.5 & -179.3 & -18.4 & 8.5 & 9.9 & 0.1 & 4.7 & 5.2 \\
\hline & B2PLYP-Z ${ }^{a}$ & -211.9 & -184.1 & -182.3 & -192.7 & -16.1 & 7.5 & 8.7 & 0.1 & 4.7 & 5.2 \\
\hline & Expt $[93]$ & -199 & -178 & -178 & -185 & -14 & 7 & 7 & & & \\
\hline $\mathrm{MnO}_{3}$ & $\mathrm{BP}$ & 1875.7 & 1880.0 & 2187.2 & 1981.0 & -100.1 & -96.5 & 196.6 & -18.2 & -17.5 & -3.3 \\
\hline $\mathrm{S}=1 / 2$ & B3LYP & -103.6 & -100.1 & -10.1 & -71.2 & -21.4 & -21.1 & 42.5 & -26.8 & -23.7 & 2.7 \\
\hline & TPSS & 1793.2 & 1797.4 & 2086.9 & 1892.5 & -94.9 & -91.2 & 186.1 & -16.3 & -15.8 & -3.6 \\
\hline & TPSSh & 1618.0 & 1623.8 & 1953.1 & 1731.6 & -109.5 & -104.2 & 213.7 & -17.3 & -16.8 & -5.4 \\
\hline & B2PLYP & 1133.0 & 1208.2 & 1559.0 & 1300.1 & -153.5 & -90.1 & 243.7 & -53.3 & -41.6 & -24.5 \\
\hline & B2PLYP-Z ${ }^{a}$ & 990.8 & 1254.2 & 1613.0 & 1286.1 & -149.3 & -87.2 & 236.7 & -53.3 & -41.6 & -24.5 \\
\hline & Expt $[94]$ & 1532 & 1532 & 1775 & 1613 & -81 & -81 & 162 & & & \\
\hline$\left[\mathrm{Cu}\left(\mathrm{NH}_{3}\right)_{4}\right]^{2+}$ & BP & -553.3 & -39.9 & -39.8 & -211.0 & -419.2 & 209.5 & 209.6 & 163.3 & 48.1 & 48.0 \\
\hline $\mathrm{S}=1 / 2$ & B3LYP & -628.9 & -56.7 & -56.6 & -247.4 & -488.1 & 244.0 & 244.2 & 226.3 & 66.4 & 66.4 \\
\hline & TPSS & -590.5 & -46.7 & -46.6 & -227.9 & -432.9 & 216.4 & 216.5 & 152.0 & 46.4 & 46.4 \\
\hline & TPSSh & -647.3 & -71.6 & -71.4 & -263.4 & -465.7 & 232.7 & 232.9 & 176.6 & 54.0 & 54.0 \\
\hline & B2PLYP & -548.4 & -40.3 & -40.1 & -209.6 & -510.9 & 255.3 & 255.6 & 357.0 & 98.9 & 98.8 \\
\hline & B2PLYP-Z a & -592.1 & -91.2 & -91.0 & -258.0 & -506.4 & 253.1 & 253.3 & 357.0 & 98.9 & 98.8 \\
\hline & Expt [95] & $(-) 586$ & $(-) 27$ & $(-) 27$ & & & & & & & \\
\hline$\left[\mathrm{Cu}(\mathrm{dtc})_{2}\right]$ & $\mathrm{BP}$ & -413.7 & -70.0 & -65.9 & -183.2 & -275.9 & 136.6 & 139.3 & 96.6 & 27.7 & 29.1 \\
\hline $\mathrm{S}=1 / 2$ & B3LYP & -512.3 & -114.9 & -109.8 & -245.7 & -331.6 & 164.1 & 167.5 & 136.7 & 38.4 & 40.1 \\
\hline & TPSS & -445.1 & -77.3 & -73.9 & -198.8 & -291.3 & 144.4 & 146.8 & 96.9 & 29.0 & 30.0 \\
\hline & TPSSh & -508.5 & -112.0 & -108.0 & -242.8 & -319.1 & 158.2 & 161.0 & 115.0 & 34.2 & 35.4 \\
\hline & B2PLYP & -424.6 & -140.9 & -134.7 & -233.4 & -316.9 & 155.7 & 161.2 & 264.8 & 75.9 & 76.6 \\
\hline & B2PLYP-Z ${ }^{a}$ & -473.8 & -179.2 & -173.4 & -275.4 & -302.9 & 162.7 & 168.1 & 264.8 & 75.9 & 76.6 \\
\hline & Expt $[96]$ & -476 & -125 & -107 & & & & & & & \\
\hline$\left[\mathrm{Cu}(\mathrm{acac})_{2}\right]$ & $\mathrm{BP}$ & -550.2 & -55.6 & -53.9 & -219.9 & -408.1 & 202.1 & 206.1 & 161.0 & 45.4 & 43.0 \\
\hline $\mathrm{S}=1 / 2$ & B3LYP & -653.6 & -72.2 & -68.7 & -264.8 & -499.8 & 247.2 & 252.6 & 232.4 & 66.7 & 64.8 \\
\hline & TPSS & -591.0 & -65.7 & -63.3 & -240.0 & -422.5 & 208.8 & 213.7 & 150.5 & 44.6 & 42.0 \\
\hline & TPSSh & -664.1 & -92.5 & -89.1 & -281.9 & -466.1 & 230.3 & 235.8 & 178.2 & 53.4 & 51.3 \\
\hline & Expt $[97,98]$ & -550 & -60 & -60 & & & & & & & \\
\hline$\left[\mathrm{Cu}(\mathrm{en})_{2}\right]^{2+}$ & $\mathrm{BP}$ & -551.4 & -63.8 & -60.9 & -225.4 & -395.1 & 195.9 & 199.2 & 145.7 & 42.3 & 41.9 \\
\hline $\mathrm{S}=1 / 2$ & B3LYP & -644.0 & -94.2 & -88.4 & -275.6 & -465.9 & 229.5 & 236.4 & 204.8 & 59.2 & 58.1 \\
\hline & TPSS & -587.3 & -72.1 & -68.3 & -242.5 & -409.2 & 202.5 & 206.7 & 137.9 & 41.4 & 41.0 \\
\hline & TPSSh & -651.0 & -102.7 & -97.3 & -283.6 & -442.8 & 218.4 & 224.5 & 161.6 & 48.7 & 47.9 \\
\hline & B2PLYP & -593.8 & -57.8 & -43.8 & -231.8 & -525.3 & 255.1 & 270.2 & 335.7 & 91.3 & 90.2 \\
\hline & B2PLYP-Z ${ }^{\mathrm{a}}$ & $\begin{array}{l}-643.2 \\
(-) 608\end{array}$ & $\begin{array}{l}-110.6 \\
(-) 83\end{array}$ & $\begin{array}{l}-97.2 \\
(-) 83\end{array}$ & -283.6 & -523.9 & 254.6 & 269.2 & 335.7 & 91.3 & 90.2 \\
\hline$\left[\mathrm{Ni}(\mathrm{CO})_{3} \mathrm{H}\right]$ & $\begin{array}{r}\text { Expt [95] } \\
\text { BP }\end{array}$ & -125.7 & $\begin{array}{r}-83 \\
12.2\end{array}$ & $\begin{array}{r}(-) 83 \\
12.2\end{array}$ & -33.8 & -99.9 & 49.9 & 50.0 & -0.6 & -12.6 & -12.6 \\
\hline $\mathrm{S}=1 / 2$ & B3LYP & -124.2 & 24.4 & 24.4 & -25.1 & -113.2 & 56.6 & 56.6 & -2.6 & -23.7 & -23.7 \\
\hline & TPSS & -127.0 & 11.6 & 11.6 & -34.6 & -100.1 & 50.0 & 50.0 & -0.8 & -12.3 & -12.3 \\
\hline & TPSSh & -126.4 & 17.4 & 17.4 & -30.5 & -105.9 & 53.0 & 53.0 & -1.6 & -16.6 & -16.6 \\
\hline & B2PLYP & -138.2 & -14.5 & -14.4 & -55.7 & -114.2 & 57.0 & 57.1 & -10.2 & -57.7 & -57.7 \\
\hline & B2PLYP-Z ${ }^{\mathrm{a}}$ & -137.7 & -17.5 & -17.5 & -57.5 & -111.4 & 55.6 & 55.7 & -10.2 & -57.7 & -57.7 \\
\hline & Expt [99] & -79 & 53 & 53 & & & & & & & \\
\hline$\left[\mathrm{Ni}(\mathrm{mnt})_{2}\right]^{-}$ & $\mathrm{BP}$ & -12.2 & -9.3 & 49.2 & 9.2 & -27.4 & -32.2 & 59.5 & -11.9 & -4.2 & -37.4 \\
\hline $\mathrm{S}=1 / 2$ & B3LYP & -18.0 & -17.3 & 41.1 & 1.9 & -38.3 & -27.3 & 65.6 & -10.6 & -20.9 & -55.4 \\
\hline & TPSS & -18.4 & -16.9 & 47.3 & 4.0 & -27.9 & -34.1 & 62.0 & -11.9 & -4.2 & -36.1 \\
\hline & TPSSh & -18.5 & -18.4 & 48.2 & 3.8 & -36.8 & -30.0 & 66.7 & -8.2 & -14.8 & -45.0 \\
\hline & Expt [100] & $<6$ & 9 & 45 & & & & & & & \\
\hline
\end{tabular}

\footnotetext{
${ }^{a} \mathrm{~A}^{(\mathrm{M})}, \mathrm{A}^{(\mathrm{M} ; \mathrm{c})}$ and $\mathrm{A}^{(\mathrm{M} ; \mathrm{d})}$ are corrected at the SCF level employing ZORA.
} 
Table 8: Metal nucleus hyperfine coupling constants in MHz.

\begin{tabular}{|c|c|c|c|c|c|c|c|c|c|c|c|}
\hline & & $\mathrm{A}_{11}^{(\mathrm{M})}$ & $\mathrm{A}_{22}^{(\mathrm{M})}$ & $\mathrm{A}_{33}^{(\mathrm{M})}$ & $\mathrm{A}^{(\mathrm{M} ; \mathrm{c})}$ & $\mathrm{A}_{11}^{(\mathrm{M} ; \mathrm{d})}$ & $\mathrm{A}_{22}^{(\mathrm{M} ; \mathrm{d})}$ & $\mathrm{A}_{33}^{(\mathrm{M} ; \mathrm{d})}$ & $\mathrm{A}_{11}^{(\mathrm{M} ; \mathrm{SO})}$ & $\mathrm{A}_{22}^{(\mathrm{M} ; \mathrm{SO})}$ & $\mathrm{A}_{33}^{(\mathrm{M} ; \mathrm{SO})}$ \\
\hline$\left[\mathrm{Fe}(\mathrm{CO})_{5}\right]^{+}$ & $\mathrm{BP}$ & -14.2 & -14.1 & 37.1 & 3.0 & -18.0 & -17.9 & 35.8 & 2.2 & 2.2 & -0.3 \\
\hline \multirow[t]{6}{*}{$\mathrm{S}=1 / 2$} & B3LYP & -16.8 & -16.7 & 36.4 & 1.0 & -19.0 & -18.9 & 37.9 & 3.3 & 3.3 & -0.5 \\
\hline & TPSS & -14.1 & -14.0 & 36.2 & 2.7 & -17.5 & -17.5 & 35.0 & 1.8 & 1.8 & -0.4 \\
\hline & TPSSh & -16.3 & -16.2 & 34.7 & 0.7 & -17.9 & -17.8 & 35.8 & 2.1 & 2.1 & -0.5 \\
\hline & B2PLYP & -21.5 & -21.4 & 33.8 & -3.1 & -20.4 & -20.3 & 40.7 & 4.7 & 4.7 & -1.1 \\
\hline & B2PLYP-Z ${ }^{a}$ & -21.3 & -21.2 & 33.3 & -3.2 & -20.7 & -20.7 & 40.0 & 4.7 & 4.7 & -1.1 \\
\hline & Expt [101] & -17 & -17 & 28 & -2 & -15 & -15 & 30 & & & \\
\hline$\left[\mathrm{Mn}(\mathrm{CO})_{5}\right]$ & $\mathrm{BP}$ & -81.4 & -70.7 & 204.9 & 17.6 & -100.5 & -89.7 & 190.1 & 2.9 & 2.9 & -1.4 \\
\hline \multirow[t]{6}{*}{$\mathrm{S}=1 / 2$} & B3LYP & -83.6 & -72.4 & 202.1 & 15.4 & -101.0 & -89.6 & 190.5 & 3.5 & 3.4 & -2.2 \\
\hline & TPSS & -80.5 & -70.1 & 196.2 & 15.2 & -96.9 & -86.5 & 183.4 & 2.0 & 2.0 & -1.7 \\
\hline & TPSSh & -85.1 & -74.4 & 190.2 & 10.3 & -96.7 & -86.0 & 182.7 & 2.0 & 2.0 & -2.1 \\
\hline & B2PLYP & -196.2 & -175.4 & 220.6 & -50.3 & -148.1 & -127.1 & 275.2 & 0.8 & 0.8 & -5.6 \\
\hline & B2PLYP-Z ${ }^{\mathrm{a}}$ & -187.0 & -166.4 & 228.6 & -41.5 & -147.5 & -126.7 & 274.1 & 0.8 & 0.8 & -5.6 \\
\hline & Expt [102] & -86 & -86 & 190 & 6 & -92 & -92 & 184 & & & \\
\hline$\left[\mathrm{Mn}\left(\mathrm{H}_{2} \mathrm{O}\right)_{6}\right]^{2+}$ & $\mathrm{BP}$ & -166.5 & -166.2 & -165.7 & -166.2 & -0.4 & -0.1 & 0.4 & -2.9 & -2.9 & -2.9 \\
\hline \multirow[t]{5}{*}{$\mathrm{S}=5 / 2$} & B3LYP & -174.0 & -173.6 & -173.0 & -173.5 & -0.4 & -0.1 & 0.6 & -2.5 & -2.5 & -2.5 \\
\hline & TPSS & -181.8 & -181.4 & -180.8 & -181.3 & -0.5 & -0.1 & 0.6 & -2.9 & -2.9 & -2.9 \\
\hline & TPSSh & -198.9 & -198.4 & -197.7 & -198.3 & -0.5 & -0.1 & 0.6 & -2.7 & -2.7 & -2.7 \\
\hline & B2PLYP & -206.0 & -205.5 & -204.8 & -205.4 & -0.5 & -0.1 & 0.6 & -2.1 & -2.1 & -2.1 \\
\hline & $\begin{array}{l}\text { B2PLYP-Z }{ }^{\mathrm{a}} \\
\text { Expt }[103]\end{array}$ & $\begin{array}{l}-225.4 \\
-245\end{array}$ & $\begin{array}{l}-225.0 \\
-245\end{array}$ & $\begin{array}{l}-224.3 \\
-245\end{array}$ & -224.9 & -0.5 & -0.1 & 0.7 & -2.1 & -2.1 & -2.1 \\
\hline$\left[\mathrm{Cr}(\mathrm{CO})_{4}\right]^{+}$ & $\begin{array}{r}\text { Expt [103] } \\
\text { BP }\end{array}$ & $\begin{array}{r}-245 \\
22.6\end{array}$ & $\begin{array}{r}-245 \\
23.2\end{array}$ & $\begin{array}{r}-240 \\
23.3\end{array}$ & 23.0 & -0.5 & 0.2 & 0.3 & 0.9 & 0.9 & 0.9 \\
\hline \multirow[t]{6}{*}{$\mathrm{S}=1 / 2$} & B3LYP & 24.8 & 25.4 & 25.5 & 25.2 & -0.4 & 0.1 & 0.3 & 0.9 & 0.9 & 0.9 \\
\hline & TPSS & 27.0 & 27.6 & 27.7 & 27.4 & -0.4 & 0.2 & 0.3 & 0.9 & 0.9 & 0.9 \\
\hline & TPSSh & 29.7 & 30.2 & 30.3 & 30.1 & -0.4 & 0.1 & 0.3 & 0.9 & 0.9 & 0.9 \\
\hline & B2PLYP & 31.1 & 32.4 & 33.1 & 32.2 & -1.1 & 0.2 & 0.9 & 0.8 & 0.8 & 0.8 \\
\hline & B2PLYP-Z a & 33.1 & 34.4 & 35.1 & 34.2 & -1.1 & 0.2 & 0.9 & 0.8 & 0.8 & 0.8 \\
\hline & Expt [104] & 42 & 42 & 42 & 42 & 0 & 0 & 0 & & & \\
\hline$\left[\mathrm{V}\left(\mathrm{H}_{2} \mathrm{O}\right)_{6}\right]^{2+}$ & $\mathrm{BP}$ & -174.0 & -170.0 & -166.7 & -170.2 & -4.0 & 0.2 & 3.8 & -8.9 & -9.0 & -9.4 \\
\hline \multirow{6}{*}{$\mathrm{S}=3 / 2$} & B3LYP & -177.3 & -173.7 & -170.6 & -173.9 & -3.7 & 0.1 & 3.6 & -9.4 & -9.7 & -10.1 \\
\hline & TPSS & -185.1 & -181.7 & -179.0 & -181.9 & -3.4 & 0.2 & 3.2 & -7.8 & -7.9 & -8.2 \\
\hline & TPSSh & -199.0 & -195.8 & -193.2 & -196.0 & -3.2 & 0.2 & 3.1 & -8.0 & -8.2 & -8.5 \\
\hline & B2PLYP & -208.5 & -205.5 & -202.8 & -205.6 & -3.4 & 0.0 & 3.3 & -11.3 & -10.4 & -10.7 \\
\hline & B2PLYP-Z ${ }^{\mathrm{a}}$ & -223.1 & -220.3 & -217.4 & -220.3 & -3.5 & -0.2 & 3.3 & -10.4 & -10.7 & -11.3 \\
\hline & Expt [105] & -247 & -247 & -247 & & & & & & & \\
\hline$\left[\mathrm{VO}\left(\mathrm{H}_{2} \mathrm{O}\right)_{5}\right]^{2+}$ & $\mathrm{BP}$ & -475.4 & -172.9 & -171.5 & -273.3 & -190.3 & 95.7 & 94.5 & -25.1 & -7.4 & -7.1 \\
\hline \multirow{6}{*}{$\mathrm{S}=1 / 2$} & B3LYP & -512.3 & -193.7 & -192.8 & -299.6 & -198.8 & 99.8 & 99.0 & -29.0 & -8.2 & -8.2 \\
\hline & TPSS & -492.8 & -194.0 & -192.8 & -293.2 & -190.0 & 95.5 & 94.5 & -21.1 & -6.7 & -6.6 \\
\hline & TPSSh & -523.2 & -220.5 & -219.5 & -321.1 & -191.8 & 96.3 & 95.5 & -22.7 & -7.1 & -7.0 \\
\hline & B2PLYP & -578.7 & -237.7 & -207.8 & -341.4 & -220.9 & 94.9 & 126.0 & -36.5 & -11.4 & -12.7 \\
\hline & B2PLYP-Z a & -595.9 & -253.7 & -225.1 & -358.2 & -221.5 & 95.7 & 125.7 & -36.5 & -11.4 & -12.7 \\
\hline & Expt [106] & -547 & -212 & -212 & & & & & & & \\
\hline \multirow[t]{6}{*}{ mean error } & $\mathrm{BP}$ & 50.3 & 47.2 & 49.9 & 71.3 & -4.6 & 1.2 & 3.4 & & & \\
\hline & B3LYP & -81.6 & -69.3 & -77.8 & -153.9 & 4.3 & 8.8 & -13.1 & & & \\
\hline & TPSS & 23.8 & 26.3 & 28.1 & 38.7 & -3.3 & 1.7 & 1.5 & & & \\
\hline & TPSSh & -5.7 & 4.8 & 9.3 & 16.3 & -4.7 & -0.1 & 4.7 & & & \\
\hline & B2PLYP & -27.9 & -26.6 & -10.9 & -42.2 & -16.0 & -3.6 & 19.6 & & & \\
\hline & B2PLYP-Z ${ }^{\mathrm{a}}$ & -38.2 & -25.5 & -8.7 & -24.8 & -15.8 & -3.8 & 19.5 & & & \\
\hline \multirow[t]{6}{*}{ mean absolute error } & $\mathrm{BP}$ & 65.7 & 62.4 & 63.0 & 86.2 & 7.8 & 5.3 & 9.8 & & & \\
\hline & B3LYP & 137.2 & 127.9 & 132.9 & 228.6 & 11.6 & 9.7 & 18.6 & & & \\
\hline & TPSS & 50.7 & 49.7 & 49.9 & 66.4 & 6.1 & 4.5 & 7.4 & & & \\
\hline & TPSSh & 42.1 & 34.8 & 36.7 & 40.3 & 7.2 & 5.7 & 10.1 & & & \\
\hline & B2PLYP & 55.2 & 48.0 & 39.7 & 54.6 & 18.0 & 7.4 & 23.5 & & & \\
\hline & B2PLYP-Z ${ }^{\mathrm{a}}$ & 63.9 & 53.7 & 41.5 & 62.1 & 16.8 & 6.6 & 21.6 & & & \\
\hline
\end{tabular}

\footnotetext{
${ }^{a} \mathrm{~A}^{(\mathrm{M})}, \mathrm{A}^{(\mathrm{M} ; \mathrm{c})}$ and $\mathrm{A}^{(\mathrm{M} ; \mathrm{d})}$ are corrected at the $\mathrm{SCF}$ level employing ZORA.
} 
Table 9: Hyperfine coupling constants in $\mathrm{MHz}$ for a series of ligand atoms.

\begin{tabular}{|c|c|c|c|c|c|c|c|c|c|}
\hline & & & $\mathrm{A}_{11}^{(\mathrm{L})}$ & $\mathrm{A}_{22}^{(\mathrm{L})}$ & $\mathrm{A}_{33}^{(\mathrm{L})}$ & $\mathrm{A}^{(\mathrm{L} ; \mathrm{c})}$ & $\mathrm{A}_{11}^{(\mathrm{L} ; \mathrm{d})}$ & $\mathrm{A}_{22}^{(\mathrm{L} ; \mathrm{d})}$ & $\mathrm{A}_{33}^{(\mathrm{L} ; \mathrm{d})}$ \\
\hline \multirow[t]{6}{*}[\mathrm{Ni}(\mathrm{CO})_{3}\mathrm{H}]{} & $\mathrm{BP}$ & ${ }^{1} \mathrm{H}$ & 315.1 & 315.1 & 321.3 & 317.2 & -2.1 & -2.1 & 4.2 \\
\hline & B3LYP & ${ }^{1} \mathrm{H}$ & 202.4 & 202.4 & 220.3 & 208.4 & -6.0 & -5.9 & 11.9 \\
\hline & TPSS & ${ }^{1} \mathrm{H}$ & 324.0 & 324.1 & 331.2 & 326.5 & -2.4 & -2.4 & 4.8 \\
\hline & TPSSh & ${ }^{1} \mathrm{H}$ & 255.3 & 255.4 & 268.1 & 259.6 & -4.3 & -4.2 & 8.5 \\
\hline & B2PLYP & ${ }^{1} \mathrm{H}$ & 520.9 & 530.0 & 530.0 & 527.0 & -6.1 & 3.1 & 3.1 \\
\hline & Expt [99] & & 287.5 & 287.5 & 304 & 293 & & & \\
\hline \multirow[t]{6}{*}[\mathrm{Mn}(\mathrm{H}_{2}\mathrm{O})_{6}]{$^{2+}$} & $\mathrm{BP}$ & ${ }^{17} \mathrm{O}$ & -12.8 & -10.6 & -9.2 & -10.8 & -1.9 & 0.3 & 1.6 \\
\hline & B3LYP & ${ }^{17} \mathrm{O}$ & -13.0 & -10.4 & -9.2 & -10.9 & -2.2 & 0.5 & 1.6 \\
\hline & TPSS & ${ }^{17} \mathrm{O}$ & -12.8 & -10.5 & -9.3 & -10.9 & -2.0 & 0.3 & 1.6 \\
\hline & TPSSh & ${ }^{17} \mathrm{O}$ & -12.1 & -9.6 & -8.5 & -10.1 & -2.0 & 0.4 & 1.6 \\
\hline & B2PLYP & ${ }^{17} \mathrm{O}$ & -11.4 & -8.4 & -7.6 & -9.2 & -2.3 & 0.7 & 1.5 \\
\hline & Expt [107] & & -9.6 & -6.5 & -6.5 & -7.5 & & & \\
\hline \multirow[t]{6}{*}[\mathrm{Cu}(\mathrm{NH}_{3})_{4}]{$^{2+}$} & $\mathrm{BP}$ & ${ }^{14} \mathrm{~N}$ & 32.6 & 32.7 & 48.9 & 38.0 & -5.4 & -5.4 & 10.8 \\
\hline & B3LYP & ${ }^{14} \mathrm{~N}$ & 31.3 & 31.4 & 45.5 & 36.0 & -4.7 & -4.7 & 9.4 \\
\hline & TPSS & ${ }^{14} \mathrm{~N}$ & 32.1 & 32.1 & 47.8 & 37.3 & -5.3 & -5.2 & 10.4 \\
\hline & TPSSh & ${ }^{14} \mathrm{~N}$ & 31.0 & 31.1 & 45.6 & 35.9 & -4.9 & -4.8 & 9.7 \\
\hline & B2PLYP & ${ }^{14} \mathrm{~N}$ & 32.8 & 32.8 & 46.5 & 37.4 & -4.6 & -4.5 & 9.1 \\
\hline & Expt [95] & & 30.7 & 30.7 & 37.2 & 32.7 & & & \\
\hline \multirow[t]{6}{*}[\mathrm{Cu}(\mathrm{en})_{2}]{} & $\mathrm{BP}$ & ${ }^{14} \mathrm{~N}$ & 25.1 & 25.2 & 43.1 & 31.1 & -6.0 & -5.9 & 11.9 \\
\hline & B3LYP & ${ }^{14} \mathrm{~N}$ & 26.3 & 26.3 & 42.3 & 31.6 & -5.4 & -5.3 & 10.7 \\
\hline & TPSS & ${ }^{14} \mathrm{~N}$ & 25.4 & 25.6 & 42.9 & 31.3 & -5.8 & -5.7 & 11.6 \\
\hline & TPSSh & ${ }^{14} \mathrm{~N}$ & 25.6 & 25.7 & 42.0 & 31.1 & -5.5 & -5.4 & 10.9 \\
\hline & B2PLYP & ${ }^{14} \mathrm{~N}$ & 24.6 & 24.7 & 39.3 & 29.6 & -4.9 & -4.9 & 9.8 \\
\hline & Expt [95] & & 25 & 25 & 33 & 28 & & & \\
\hline \multirow{6}{*}[\mathrm{Cu}(\mathrm{dtc})_{2}]{} & $\mathrm{BP}$ & ${ }^{33} \mathrm{~S}$ & 4.2 & 4.8 & 52.8 & 20.6 & -16.4 & -15.8 & 32.2 \\
\hline & B3LYP & ${ }^{33} \mathrm{~S}$ & 9.3 & 10.3 & 56.8 & 25.5 & -16.2 & -15.2 & 31.4 \\
\hline & TPSS & ${ }^{33} \mathrm{~S}$ & 8.1 & 8.6 & 55.2 & 23.9 & -15.9 & -15.3 & 31.2 \\
\hline & TPSSh & ${ }^{33} \mathrm{~S}$ & 9.8 & 10.5 & 55.9 & 25.4 & -15.6 & -14.9 & 30.5 \\
\hline & B2PLYP & ${ }^{33} \mathrm{~S}$ & 16.0 & 17.6 & 71.1 & 34.9 & -18.9 & -17.3 & 36.2 \\
\hline & Expt [96] & & 22 & 27 & 65 & & & & \\
\hline \multirow{5}{*}[\mathrm{Ni}(\mathrm{mnt})_{2}]{$^{-}$} & $\mathrm{BP}$ & ${ }^{33} \mathrm{~S}$ & -11.7 & -10.0 & 33.8 & 4.0 & -15.7 & -14.0 & 29.7 \\
\hline & B3LYP & ${ }^{33} \mathrm{~S}$ & -10.6 & -7.1 & 41.7 & 8.0 & -18.6 & -15.1 & 33.7 \\
\hline & TPSS & ${ }^{33} \mathrm{~S}$ & -8.2 & -5.8 & 37.5 & 7.8 & -16.0 & -13.7 & 29.7 \\
\hline & TPSSh & ${ }^{33} \mathrm{~S}$ & -8.1 & -4.7 & 40.2 & 9.2 & -17.2 & -13.8 & 31.1 \\
\hline & Expt [100] & & -13.5 & -13.5 & 43 & & & & \\
\hline \multirow{6}{*}[\mathrm{Cr}(\mathrm{CO})_{4}]{$^{+}$} & $\mathrm{BP}$ & ${ }^{13} \mathrm{C}$ & -13.8 & -13.7 & -10.9 & -12.8 & -1.0 & -0.9 & 1.9 \\
\hline & B3LYP & ${ }^{13} \mathrm{C}$ & -12.0 & -11.9 & -8.1 & -10.7 & -1.3 & -1.3 & 2.6 \\
\hline & TPSS & ${ }^{13} \mathrm{C}$ & -11.3 & -11.3 & -8.3 & -10.3 & -1.0 & -1.0 & 2.0 \\
\hline & TPSSh & ${ }^{13} \mathrm{C}$ & -13.3 & -13.2 & -9.9 & -12.1 & -1.2 & -1.1 & 2.3 \\
\hline & B2PLYP & ${ }^{13} \mathrm{C}$ & -10.2 & -9.9 & -5.8 & -8.6 & -1.6 & -1.2 & 2.8 \\
\hline & Expt [104] & & -15.5 & -15.5 & -12.5 & -13.5 & & & \\
\hline \multirow[t]{12}{*}[\mathrm{Fe}(\mathrm{CO})_{5}]{$^{+}$} & $\mathrm{BP}$ & ${ }^{13} \mathrm{C}$ & 55.7 & 55.7 & 63.5 & 58.3 & -2.6 & -2.6 & 5.2 \\
\hline & B3LYP & ${ }^{13} \mathrm{C}$ & 25.5 & 25.5 & 30.7 & 27.2 & -1.7 & -1.7 & 3.5 \\
\hline & TPSS & ${ }^{13} \mathrm{C}$ & 43.6 & 43.6 & 49.6 & 45.6 & -2.0 & -2.0 & 4.0 \\
\hline & TPSSh & ${ }^{13} \mathrm{C}$ & 27.8 & 27.8 & 32.4 & 29.3 & -1.5 & -1.5 & 3.1 \\
\hline & B2PLYP & ${ }^{13} \mathrm{C}$ & 55.6 & 55.8 & 63.3 & 58.3 & -2.6 & -2.4 & 5.1 \\
\hline & Expt [101] & & 50.7 & 50.7 & 59.1 & 53.5 & & & \\
\hline & $\mathrm{BP}$ & ${ }^{13} \mathrm{C}$ & -24.4 & -21.9 & -15.4 & -20.6 & -3.9 & -1.3 & 5.2 \\
\hline & B3LYP & ${ }^{13} \mathrm{C}$ & -28.6 & -27.5 & -19.6 & -25.2 & -3.4 & -2.2 & 5.6 \\
\hline & TPSS & ${ }^{13} \mathrm{C}$ & -26.4 & -24.1 & -17.2 & -22.5 & -3.9 & -1.5 & 5.4 \\
\hline & TPSSh & ${ }^{13} \mathrm{C}$ & -30.0 & -28.3 & -20.8 & -26.4 & -3.6 & -2.0 & 5.6 \\
\hline & B2PLYP & ${ }^{13} \mathrm{C}$ & -31.3 & -30.5 & -22.5 & -28.1 & -3.2 & -2.4 & 5.6 \\
\hline & Expt [101] & & -25.4 & -25.4 & -18.6 & -23.0 & -2.2 & -2.2 & 4.4 \\
\hline \multirow[t]{5}{*}{ mean error $^{a}$} & $\mathrm{BP}$ & & -1.2 & -1.3 & 0.9 & 2.2 & & & \\
\hline & B3LYP & & -4.5 & -4.5 & -2.4 & -3.7 & & & \\
\hline & TPSS & & -1.7 & -1.8 & -0.2 & 0.0 & & & \\
\hline & TPSSh & & -4.2 & -4.1 & -2.8 & -3.8 & & & \\
\hline & B2PLYP & & -0.3 & -0.6 & 3.9 & 1.5 & & & \\
\hline \multirow[t]{5}{*}{ mean absolute error ${ }^{a}$} & BP & & 4.1 & 5.3 & 6.9 & 3.3 & & & \\
\hline & B3LYP & & 6.6 & 7.5 & 7.9 & 6.9 & & & \\
\hline & TPSS & & 4.6 & 5.6 & 6.7 & 3.8 & & & \\
\hline & TPSSh & & 6.3 & 7.2 & 7.9 & 6.3 & & & \\
\hline & B2PLYP & & 3.8 & 4.2 & 5.4 & 3.8 & & & \\
\hline
\end{tabular}

${ }^{a}$ Statistics excluding ${ }^{1} \mathrm{H}$ in $\left[\mathrm{Ni}(\mathrm{CO}){ }_{3} \mathrm{H}\right]$. 
Table 10: Hyperfine coupling constants in MHz for selected radicals. The structures were optimized with the same functional with which the HFCs are calculated.

\begin{tabular}{|c|c|c|c|c|c|c|c|c|c|}
\hline & & & $\mathrm{A}_{11}^{(\mathrm{A})}$ & $\mathrm{A}_{22}^{(\mathrm{A})}$ & $\mathrm{A}_{33}^{(\mathrm{A})}$ & $\mathrm{A}^{(\mathrm{A} ; \mathrm{c})}$ & $\mathrm{A}_{11}^{(\mathrm{A} ; \mathrm{d})}$ & $\mathrm{A}_{22}^{(\mathrm{A} ; \mathrm{d})}$ & $\mathrm{A}_{33}^{(\mathrm{A} ; \mathrm{d})}$ \\
\hline \multirow{6}{*}[\mathrm{Mn}(\mathrm{H}_{2}\mathrm{O})_{6}]{$^{2+}$} & $\mathrm{BP}$ & ${ }^{55} \mathrm{Mn}$ & -167.1 & -167.0 & -167.0 & -167.0 & 0.0 & 0.0 & 0.0 \\
\hline & B3LYP & ${ }^{55} \mathrm{Mn}$ & -174.7 & -174.7 & -174.7 & -174.7 & 0.0 & 0.0 & 0.0 \\
\hline & TPSS & ${ }^{55} \mathrm{Mn}$ & -181.8 & -181.4 & -180.8 & -181.3 & -0.5 & -0.1 & 0.6 \\
\hline & TPSSh & ${ }^{55} \mathrm{Mn}$ & -199.2 & -199.2 & -199.2 & -199.2 & 0.0 & 0.0 & 0.0 \\
\hline & B2PLYP & ${ }^{55} \mathrm{Mn}$ & -233.8 & -233.8 & -233.8 & -233.8 & 0.0 & 0.0 & 0.0 \\
\hline & Expt [103] & & -245 & -245 & -245 & & & & \\
\hline \multirow{5}{*}[\mathrm{Cu}(\mathrm{NH}_{3})_{4}]{$^{2+}$} & $\mathrm{BP}$ & ${ }^{63} \mathrm{Cu}$ & -573.8 & -50.9 & -50.9 & -225.2 & -424.3 & 212.2 & 212.2 \\
\hline & B3LYP & ${ }^{63} \mathrm{Cu}$ & -647.7 & -68.6 & -68.6 & -261.7 & -491.9 & 245.9 & 245.9 \\
\hline & TPSS & ${ }^{63} \mathrm{Cu}$ & -590.5 & -46.7 & -46.6 & -227.9 & -432.9 & 216.4 & 216.5 \\
\hline & TPSSh & ${ }^{63} \mathrm{Cu}$ & -670.6 & -84.2 & -84.2 & -279.7 & -470.5 & 234.3 & 235.3 \\
\hline & $\begin{array}{l}\text { B2PLYP } \\
\text { Expt [95] }\end{array}$ & ${ }^{63} \mathrm{Cu}$ & $\begin{array}{l}-593.9 \\
(-) 586\end{array}$ & $\begin{array}{l}-42.8 \\
(-) 27\end{array}$ & $\begin{array}{l}-42.6 \\
(-) 27\end{array}$ & -226.4 & -532.5 & 266.2 & 266.3 \\
\hline \multirow[t]{12}{*}{$\mathrm{HCO}$} & $\mathrm{BP}$ & ${ }^{13} \mathrm{C}$ & 327.9 & 333.1 & 460.6 & 373.9 & -46.0 & -40.7 & 86.7 \\
\hline & B3LYP & ${ }^{13} \mathrm{C}$ & 340.8 & 346.2 & 480.1 & 389.0 & -48.3 & -42.8 & 91.1 \\
\hline & TPSS & ${ }^{13} \mathrm{C}$ & 323.9 & 334.8 & 464.4 & 374.4 & -50.5 & -39.6 & 90.0 \\
\hline & TPSSh & ${ }^{13} \mathrm{C}$ & 323.5 & 335.1 & 466.6 & 375.0 & -51.6 & -40.0 & 91.5 \\
\hline & B2PLYP & ${ }^{13} \mathrm{C}$ & 337.1 & 343.7 & 475.5 & 385.4 & -48.3 & -41.8 & 90.1 \\
\hline & Expt [46] & & $\sim 337$ & $\sim 353$ & $\sim 437$ & $365-377$ & $-39--48$ & $-12--24$ & $50-72$ \\
\hline & $\mathrm{BP}$ & ${ }^{1} \mathrm{H}$ & 351.7 & 359.3 & 389.0 & 366.7 & -15.0 & -7.3 & 22.4 \\
\hline & B3LYP & ${ }^{1} \mathrm{H}$ & 364.4 & 372.5 & 403.7 & 380.2 & -15.8 & -7.7 & 23.5 \\
\hline & TPSS & ${ }^{1} \mathrm{H}$ & 389.4 & 396.3 & 424.4 & 403.4 & -14.0 & -7.1 & 21.0 \\
\hline & TPSSh & ${ }^{1} \mathrm{H}$ & 387.5 & 394.6 & 423.1 & 401.8 & -14.2 & -7.1 & 21.3 \\
\hline & B2PLYP & ${ }^{1} \mathrm{H}$ & 358.9 & 367.2 & 398.5 & 374.9 & -15.9 & -7.6 & 23.6 \\
\hline & Expt [46] & & $\sim(-) 377$ & -) 377 & $\sim(-) 343$ & $(-) 354-(-) 381$ & -9 & -9 & 25 \\
\hline \multirow[t]{12}{*}{$\mathrm{H}_{2} \mathrm{CO}^{+}$} & $\mathrm{BP}$ & ${ }^{13} \mathrm{C}$ & -106.7 & -79.5 & -67.2 & -84.4 & -22.3 & 4.9 & 17.3 \\
\hline & B3LYP & ${ }^{13} \mathrm{C}$ & -116.2 & -86.3 & -81.4 & -94.6 & -21.6 & 8.4 & 13.3 \\
\hline & TPSS & ${ }^{13} \mathrm{C}$ & -133.1 & -105.7 & -99.7 & -112.8 & -20.3 & 7.1 & 13.2 \\
\hline & TPSSh & ${ }^{13} \mathrm{C}$ & -136.2 & -107.0 & -104.5 & -115.9 & -20.3 & 8.9 & 11.4 \\
\hline & B2PLYP & ${ }^{13} \mathrm{C}$ & -127.5 & -99.2 & -96.1 & -107.6 & -19.9 & 8.4 & 11.5 \\
\hline & Expt [30] & & -124 & -105 & -99 & -109 & -15 & 4 & 10 \\
\hline & $\mathrm{BP}$ & ${ }^{1} \mathrm{H}$ & 373.7 & 374.9 & 403.8 & 384.1 & -10.4 & -9.3 & 19.7 \\
\hline & B3LYP & ${ }^{1} \mathrm{H}$ & 355.8 & 357.6 & 383.9 & 365.8 & -9.9 & -8.2 & 18.1 \\
\hline & TPSS & ${ }^{1} \mathrm{H}$ & $\begin{array}{l}300.0 \\
374.4\end{array}$ & 375.3 & 400.1 & $\begin{array}{l}303.0 \\
383.3\end{array}$ & -8.9 & -0.2 & 16.8 \\
\hline & TPSSh & ${ }^{1} \mathrm{H}$ & 361.8 & 362.9 & 386.3 & 370.3 & -8.5 & -7.4 & 15.9 \\
\hline & B2PLYP & ${ }^{1} \mathrm{H}$ & 353.4 & 355.0 & 380.8 & 363.1 & -9.7 & -8.1 & 17.7 \\
\hline & Expt [30] & & 363 & 376 & 377 & 372 & -9 & 4 & 5 \\
\hline \multirow{10}{*}{$\mathrm{H}_{2} \mathrm{O}^{+}$} & BP & ${ }^{17} \mathrm{O}$ & -347.8 & 117.9 & 122.0 & -35.9 & -311.8 & 153.9 & 158.0 \\
\hline & B3LYP & ${ }^{17} \mathrm{O}$ & -376.3 & 88.6 & 92.8 & -65.0 & -311.3 & 153.6 & 157.7 \\
\hline & TPSS & ${ }^{17} \mathrm{O}$ & -385.2 & 81.0 & 86.9 & -72.5 & -312.8 & 153.5 & 159.3 \\
\hline & TPSSh & ${ }^{17} \mathrm{O}$ & -389.5 & 75.0 & 81.0 & -77.8 & -311.6 & 152.8 & 158.8 \\
\hline & $\begin{array}{l}\text { B2PLYP } \\
\text { Expt [31] }\end{array}$ & ${ }^{17} \mathrm{O}$ & -385.2 & 73.9 & 78.4 & $\begin{array}{l}-77.6 \\
-83\end{array}$ & -307.6 & 151.6 & 156.0 \\
\hline & $\begin{array}{r}\mathrm{BP} \\
\mathrm{B}\end{array}$ & ${ }^{1} \mathrm{H}$ & -130.2 & -88.9 & 17.9 & -67.1 & -63.2 & -21.8 & 85.0 \\
\hline & B3LYP & ${ }^{1} \mathrm{H}$ & -136.1 & -93.7 & 16.9 & -71.0 & -65.1 & -22.7 & 87.8 \\
\hline & TPSS & ${ }^{1} \mathrm{H}$ & -132.4 & -90.7 & 17.0 & -68.7 & -63.7 & -22.0 & 85.7 \\
\hline & TPSSh & ${ }^{1} \mathrm{H}$ & -136.7 & -93.9 & 15.2 & -71.8 & -64.9 & -22.1 & 87.0 \\
\hline & $\begin{array}{l}\text { B2PLYP } \\
\text { Expt [31] }\end{array}$ & ${ }^{1} \mathrm{H}$ & -141.5 & -97.8 & -13.8 & $\begin{array}{l}-75.2 \\
-73\end{array}$ & -66.3 & -22.6 & 89.0 \\
\hline \multirow[t]{5}{*}{$\mathrm{O}_{2} \mathrm{H}$} & $\mathrm{BP}$ & ${ }^{1} \mathrm{H}$ & -45.3 & -36.0 & 10.1 & -23.7 & -21.6 & -12.3 & 33.9 \\
\hline & B3LYP & ${ }^{1} \mathrm{H}$ & -47.0 & -38.6 & 8.7 & -25.6 & -21.4 & -13.0 & 34.4 \\
\hline & TPSS & ${ }^{1} \mathrm{H}$ & -39.3 & -30.6 & 13.7 & -18.7 & -20.6 & -11.8 & 32.4 \\
\hline & TPSSh & ${ }^{1} \mathrm{H}$ & -40.9 & -32.4 & 12.4 & -20.3 & -20.6 & -12.1 & 32.7 \\
\hline & $\begin{array}{l}\text { B2PLYP } \\
\text { Expt [83] }\end{array}$ & ${ }^{1} \mathrm{H}$ & -50.4 & -41.6 & 6.8 & -28.4 & $\begin{array}{l}-22.0 \\
-11\end{array}$ & $\begin{array}{c}-13.2 \\
-8\end{array}$ & $\begin{array}{l}35.2 \\
20\end{array}$ \\
\hline \multirow[t]{12}{*}{$\mathrm{NO}_{2}$} & $\mathrm{BP}$ & ${ }^{14} \mathrm{~N}$ & 125.1 & 126.7 & 180.8 & 144.2 & -19.1 & -17.5 & 36.6 \\
\hline & B3LYP & ${ }^{14} \mathrm{~N}$ & 123.3 & 126.0 & 186.5 & 145.3 & -22.0 & -19.3 & 41.2 \\
\hline & TPSS & ${ }^{14} \mathrm{~N}$ & 124.1 & 126.7 & 182.3 & 144.3 & -20.3 & -17.7 & 38.0 \\
\hline & TPSSh & ${ }^{14} \mathrm{~N}$ & 121.8 & 125.0 & 183.6 & 143.5 & -21.6 & -18.4 & 40.1 \\
\hline & B2PLYP & ${ }^{14} \mathrm{~N}$ & 129.0 & 131.9 & 187.7 & 149.5 & -20.5 & -17.6 & 38.2 \\
\hline & Expt [46] & & 131 & 138 & 190 & 153 & -22 & -15 & 37 \\
\hline & $\mathrm{BP}$ & ${ }^{17} \mathrm{O}$ & -154.3 & 9.6 & 12.2 & -44.2 & -110.1 & 53.8 & 56.3 \\
\hline & B3LYP & ${ }^{17} \mathrm{O}$ & -165.6 & 1.6 & 3.6 & -53.5 & -112.2 & 55.0 & 57.1 \\
\hline & TPSS & ${ }^{17} \mathrm{O}$ & -165.4 & 3.1 & 5.2 & -52.3 & -113.0 & 55.5 & 57.6 \\
\hline & TPSSh & ${ }^{17} \mathrm{O}$ & -167.0 & 1.9 & 3.9 & -53.7 & -113.3 & 55.6 & 57.6 \\
\hline & B2PLYP & ${ }^{17} \mathrm{O}$ & -170.2 & -8.6 & -4.9 & -61.3 & -108.9 & 52.6 & 56.3 \\
\hline & Expt [46] & & $\sim-160$ & $\sim-7$ & $\sim 5$ & $-47--61$ & -106 & 47 & 59 \\
\hline
\end{tabular}




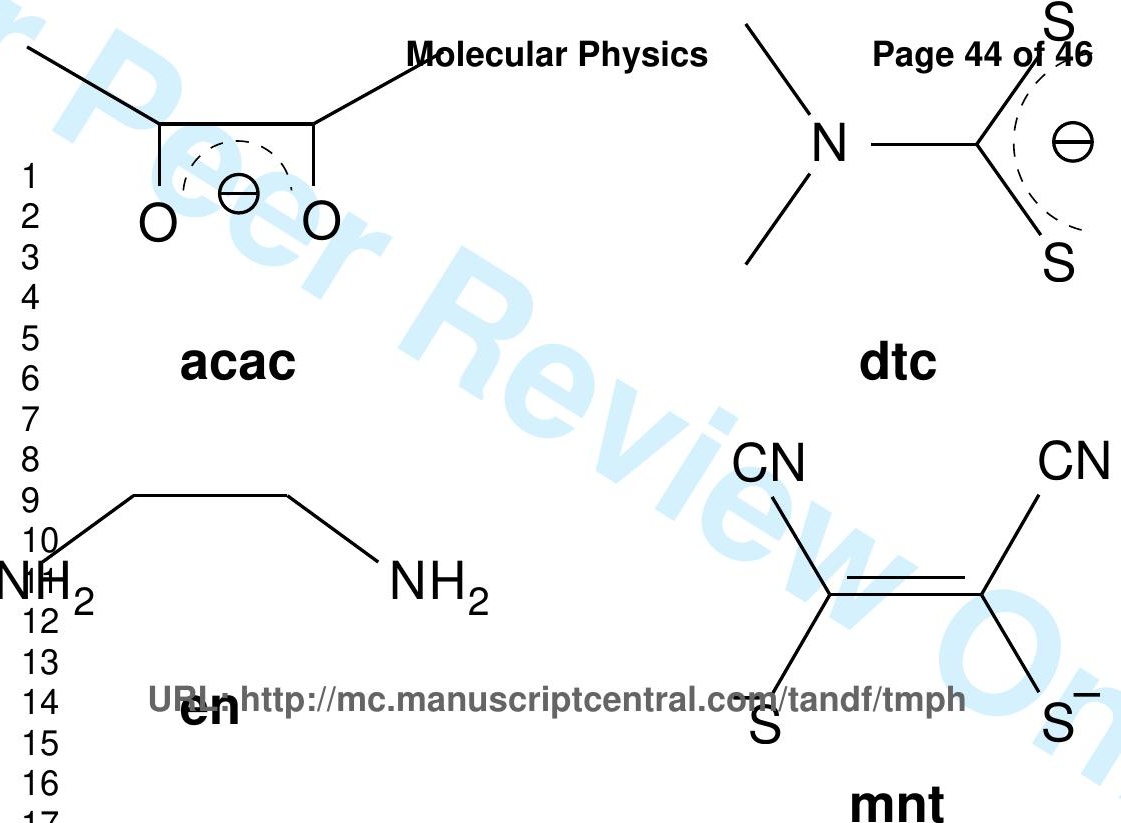




\section{Molecular Physics}

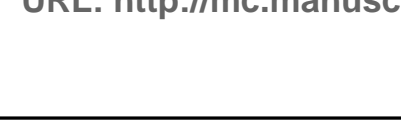


